\title{
Sovereign Ratings and National Culture
}

\author{
Huong Dang ${ }^{a}$ and Graham Partington ${ }^{b}$ \\ ${ }^{a}$ University of Canterbury, Department of Economics and Finance, Christchurch 8140, New \\ Zealand

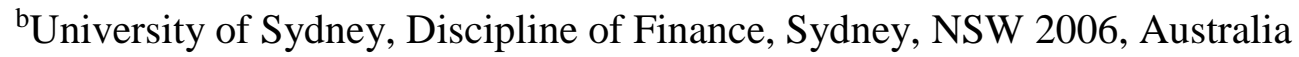 \\ Forthcoming in Pacific-Basin Finance Journal
}

\begin{abstract}
Default by sovereign governments depends upon their willingness to default and the nation's capacity to pay. These are major factors considered by rating analysts and both may be affected by national culture. We hypothesise that ratings are related to culture and empirically examine the relation between culture and both levels and changes in sovereign ratings. Sovereign ratings have traditionally been modelled in terms of macro-economic variables, rating outlook and rating history. Culture variables are significant when included in such models and their addition results in better models as judged by the QIC statistic and likelihood ratio tests. The significance of culture variables is robust to replication and to estimation using instrumental variables.

JEL Classification: G24
\end{abstract}

Keywords: sovereign debt; sovereign rating; national culture; rating history; rating outlook; rating changes.

Email addresses: ${ }^{a}$ huong.dang@canterbury.ac.nz (H. Dang). Corresponding author. bgraham.partington@sydney.edu.au (G. Partington).

The authors would like to thank the editor Robert Faff and an anonymous reviewer for constructive suggestions. Huong Dang would like to thank the financial support from Glenn Boyle and the Department of Economics and Finance, University of Canterbury. 


\section{Sovereign Ratings and National Culture}

\section{Introduction}

Sovereign rating regrades can lead to the re-balancing of international portfolios and have a substantial impact on a country's cost of financing (Bissoondoyal-Bheenick, 2005). Sovereign ratings also affect the ratings and yields of debt issued by corporate borrowers domiciled in the sovereign state (Cantor and Packard, 1996). Consequently, levels and changes in sovereign ratings are a matter of significant interest.

Governments can choose either to honour debt agreements or to default. Thus, sovereign risk reflects not just capacity to pay, but also willingness to pay (Eaton, Gersovitz and Stiglitz, 1986; Clark and Zenaidi, 1999; S\&P RatingsDirect 2013). Giving attention to willingness to pay in sovereign ratings directly articulates with traditional credit assessment, where the first of the $5 \mathrm{Cs}$ of credit analysis is character.

We argue that national character, as reflected in culture, can affect both willingness and capacity to pay. Consistent with this, El Ghoul and Zheng (2016) find that borrowers in more masculine cultures are more likely to act opportunistically at the expense of lenders. National culture may also affect the ease with which negotiations to avoid a default can be successfully concluded (Guiso, Herrera, and Morelli, 2016). Attempts to define and measure national character can generally be traced back to culture. Thus, we follow researchers such as Nakata and Sivakumar (1996) and Hofstede, Hofstede and Minkov (2010), and treat national character and national culture as synonymous.

There is increasing recognition of the role that culture plays in financial decision making and we give some examples in the next section. With respect to government decisions national culture will also affect whether decisions are palatable to the population. Politicians must translate the values and attitudes dominant in a country into political priorities. It is politically 
unpalatable to pursue strategies contrary to deeply rooted cultural norms in a country. For example, the Greek and German government's decisions during the Greek debt crisis were influenced by the nature of their cultures (Guiso et al., 2016, Jordan, 2017).

Culture may have played a role in the Greek debt crisis, but it is not so clear how that role could be quantified. In this paper we undertake a quantitative analysis of the effect of culture on sovereign debt ratings based on culture measures developed by Hofstede (1980) and Hofstede et al. (2010). The measures used are: Power distance; Collectivism versus individualism; Femininity versus masculinity; Uncertainty avoidance; Long-term versus short-term orientation We examine whether national culture affects a nation's rating grade and whether national culture affects the probability and timing of changes in that rating. There has been prior work on modelling sovereign rating grades and sovereign rating changes, for example Cantor and Packard (1996), Hill, Brooks and Faff (2010), Afonso, Gomes and Rother (2011), Alsakka and ap Gwilym (2012), and Reusens and Croux (2017). However, such work has not examined the role of culture, but rather has focused on the impact of economic variables and aspects of rating history and rating outlook. We extend this research by considering the effect of culture after controlling for variables that have been found to be significant in prior literature. As far as we can ascertain, there is only one published work, Fuchs and Gehring (2017), that attempts to use culture in the analysis of sovereign ratings. Their work is distinct from our work in that they analyse bias in ratings using measures of culture similarity (a common language, or a smaller linguistic distance). In contrast we model ratings rather than bias and use Hofstede's cultural characteristics for the nation being rated. Fuchs and Gehring only look at rating grades, whereas our work models both rating grades and changes in those grades.

There are also distinct differences in the nature of the empirical modelling. Fuchs and Gehring build linear regression models. In contrast, and consistent with the literature, we use non-linear probability models which are more appropriate to the analysis of categorical 
dependent variables.

Our study analyses Standard and Poor's (S\&P) sovereign ratings from February 1975 to June 2013 covering 77 countries. We replicate this study using Moody's data from April 1974 to June 2013 covering 72 countries. ${ }^{1}$ We estimate ordered probit models for rating levels using the technique of Generalised Estimating Equations (GEE) and we use Cox's hazard model for the analysis of rating changes. The estimation techniques are both semi-parametric and thus provide more robust estimates. The models are expressed as a function of culture, controlling for the effect of economic variables, a history of prior defaults, rating history, and rating outlook.

We find that culture is a significant determinant of sovereign ratings and the probability of a change in those ratings. The findings are robust to the use of instrumental variables and additional controls. The addition of cultural variables to the variables traditionally used to model ratings and rating changes results in better models according to the QIC statistic and likelihood ratio tests, respectively. Some cultural characteristics can have a substantial effect. For example, a shift from collectivism to individualism increases the chance of an S\&P rating upgrade by more than $60 \%$. This is a very unlikely shift for a nation but it is a feasible tilt for an international bond portfolio.

The most consistently significant cultural characteristics were individualism and a long-term orientation. These were significant for both S\&P and Moody's ratings. Individualism and a long-term orientation make upgrades more likely and downgrades less likely. National cultures are extremely stable over time (Hofstede, 2001) and it may take many decades or even centuries for fundamental shifts in culture to occur. ${ }^{2}$ Thus, over extended periods,

\footnotetext{
${ }^{1}$ The study periods were dictated by the rating data available to us and the availability of macroeconomic data used as controls.

${ }^{2}$ Cultures may shift over a long period of time but the differences and relative rankings between cultures remain intact (Hofstede, 2001). Beugelsdijk, Maseland and van Hoorn (2015) confirm this latter result.
} 
countries may be culturally predisposed towards a higher, intermediate, or lower rating, and to rating changes in a particular direction, up, or down.

The paper's contribution is three-fold. First, we provide robust evidence that culture is a determinant of S\&P's and Moody's rating levels and rating changes. Second, we employ semi-parametric techniques (GEE and stratified Cox's hazard model) to model rating levels and rating changes, respectively. Our modelling controls for potential dependence among rating observations of the same country and provide more robust estimates than parametric techniques. Third, in the context of sovereign rating analysis, we are the first to employ instrumental variables and the two-stage residual inclusion procedure to address potential endogeneity of culture.

The remainder of this paper is structured as follows. Section 2 discusses links between national culture and financial decision making and suggests how national culture may affect ratings. This is followed by a discussion of the dimensions along which national culture is measured. Section 3 presents the method of analysis and the data. Section 4 presents the empirical results and Section 5 summarises the key findings of the study.

\section{Culture and sovereign ratings}

\subsection{Culture and financial decision making}

Stulz and Williamson (2003) suggest that culture influences financial decision-making in three ways. First, culture affects values, this affects attitudes and then behaviours. Second, culture may change the intent of the law. Third, culture impacts on the allocations of resources in a country.

National culture affects financial decision making at both macro and micro levels. Culture impacts on variables that affect sovereign ratings, for example, international trade (Kristjánsdóttir, Guðlaugsson, Guðmundsdóttir, Aðalsteinsson, 2017), foreign direct 
investment (Guiso, Sapienza, Zingales, 2009; Lucke and Eichler, 2016), and exports (Chung, 2007). It also affects economic growth, national savings, GNI (Hofstede et al., 2010; Maridal, 2013), corruption and tax evasion (Husted, 1999; Tsakumis, Curatola, Porcano, 2007).

Culture has also been used to explain cross-country differences in corporate risk taking (Li, Griffin, Yue, Zhao, 2013), corporate capital structure (Chui, Lloyd, Kwok, 2002), bank risk taking (Ashraf, Zheng, Arshad, 2016), bank capital structure (Haq, Hu, Faff, Pathan, 2018), and bank failures (Berger, Xinming, Morris, Roman, 2018). Culture also influences the adoption of bank-based vs stock market-based financial system (Kwok and Tadesse, 2006), investor legal rights (Licht, Goldschmidt, Schwartz, 2005), and mortgages defaults (Tajaddini and Gholipour, 2017). Of particular relevance to our study is the work of Dang (2018) who shows that national culture affects the probability of changes in corporate ratings. ${ }^{3}$

The Greek sovereign debt crisis is one striking example where culture has been argued to play a major role. According to Jordan (2017), Greece's collectivistic culture implies that it expects friends to help by offering "softer repayment terms" or forgiving its debts, and "to break the rules when needed." While Guiso et al. (2016) suggest that culture explains Germany's angry reaction towards Greece for hiding substantial fiscal deficits. Germany's individualistic culture implies that Germans do not tolerate breaking the rules (Jordan). The above discussion suggests that national culture can affect governments' decisions about sovereign debt. Also, S\&P uses culture related variables in determining sovereign ratings (S\&P RatingsDirect, 2013).

Previous studies modelling the level of sovereign ratings have utilised economic and financial variables, whether there has been a prior default and to a lesser extent, political and

\footnotetext{
${ }^{3}$ Dang (2018)'s work has close parallels with our paper, but Dang's study is limited to corporate rating data and only investigates changes in corporate ratings, with no consideration of the determination of rating levels. In this study, we go beyond Dang's study and examine the effects of culture on sovereign rating levels and sovereign rating changes.
} 
institutional factors, see for example, Cantor and Packard (1996), Afonso (2003),

Bissoondoyal-Bheenick (2005), Afonso et al. (2011), and Reusens and Croux (2017). Studies of changes in sovereign ratings have primarily focused on macro-economic variables, rating history including momentum and rating outlook/CreditWatch variables, Alsakka and ap Gwilym (2012) and Hill et al. (2010). We use these traditional variables in our modelling of ratings and rating changes, and we add variables measuring national culture.

\subsection{Ratings and culture}

The credit rating market is dominated by two firms, Standard and Poor's (S\&P) and Moody's Investors Service (Moody's). In this paper we start by examining ratings supplied by S\&P because, according to Correa, Lee, Sapriza, and Suarez (2014, p. 98) their rating changes “... are more frequent, tend not to be anticipated by the market and tend to precede the changes of other rating agencies." Alsakka and ap Gwilym (2010) also find that S\&P tends to be the most independent of the various agencies.

Culture may affect rating grades and rating regrades through three channels. First by direct consideration of cultural factors in the analyst's assessment of sovereign risk. Second by influencing the analyst's assessment of a sovereign's economic performance. Third, if culture affects ratings through the first two channels then it also affects rating history, and this in turn influences the current rating.

Rating agencies are required to disclose the basis on which they form their ratings. To this end, S\&P RatingsDirect (2013) explain that sovereign ratings depend upon both willingness and capacity to pay, and describe the main factors in their rating process as follows (pp. 3-4):

- "Institutional and governance effectiveness and security risks, reflected in the institutional and governance effectiveness score.

- Economic structure and growth prospects, reflected in the economic score.

- External liquidity and international investment position, reflected in the external score. 
- Fiscal performance and flexibility, as well as debt burden, reflected in the fiscal score.

- Monetary flexibility, reflected in the monetary score."

In S\&P's discussion of how the score is derived there is direct reference to the sovereign's debt payment culture and payment outcomes.

S\&P RatingsDirect (2013) makes frequent reference to rating criteria related to culture, such as: cohesive civil society, robustness of political institutions, stability of civil institutions, high social inclusion, transparency and accountability of institutions, unbiased enforcement of contracts and the rule of law, open debate on policy decisions, market oriented economies, level of corruption, tax compliance and so forth. Thus, the description of the rating process provides evidence that $\mathrm{S} \& \mathrm{P}$ explicitly considers variables related to culture in determining sovereign ratings.

Economic performance, which is critical to sovereign ratings, is also related to culture. The score for S\&P's economic factor is dependent on quantitative data about the performance of the economy, with emphasis on GDP per capita and growth prospects. The evidence of Hofstede et al. (2010, p. 38, 263-265) is that GNI per capita correlates positively with the extent of individualism in a culture whereas the national saving rate and the growth rate are positively correlated with the degree of long-term orientation. ${ }^{4}$ Maridal (2013) also finds that culture influences economic development, national savings, GDP, GNI, and economic growth. Thus, cultural variables relate to the economic variables upon which S\&P's economic performance score depends.

Rating agencies can observe currently available economic indicators, but in forming a rating they need to forecast how economic performance is likely to evolve over time. Analysts’ forecasts of future economic performance may be higher for those cultures which have the

\footnotetext{
${ }^{4}$ Post 1995 the result of growth rates only applied to poor countries. There was a negative correlation for wealthy countries.
} 
characteristics associated with better economic performance. Consequently, culture may have an effect on rating through its impact on expected measures of economic performance such as future GDP.

Since changes in culture are very slow, it is unlikely to be changes in national culture that explain changes in ratings. However, we argue that some cultures may tend to experience more rating changes. ${ }^{5}$ For example, in cultures where political violence is more likely, analysts may be more prone to change ratings as political tensions rise and fall. In other cases, culture may result in a directional predisposition for rating changes. For example, a culture which predisposes to better economic performance, or better protection of investors, could make upgrades more likely and downgrades less likely.

\subsection{Dimensions of culture}

In selecting measures of culture we used the culture of the sovereign nation being rated, rather than the cultural distance between the rating agency and the nation being rated. A key reason for this is because it is the cultural aspects of the sovereign nation that $\mathrm{S} \& \mathrm{P}$ use in describing their rating process. Use of the nation's culture also better matches the arguments about culture and ratings that we make above and the hypotheses we make below about the effect of specific dimensions of culture on ratings. Additionally, measuring cultural distance is more problematic than measuring culture, Shenkar (2001).

Having chosen to measure culture, the question is how it should be measured. Since the objective of the analysis is quantitative modelling this dictates the use of quantitative measures of culture. Of the quantitative measures available, we chose to use Hofstede's measures because they are the longest used measures and have been extensively validated.

\footnotetext{
${ }^{5}$ This is analogous to individuals with high blood pressure being more likely to experience strokes or heart attacks. We make this point because the technique that we use for analysing ratings changes, Cox regression, has been extensively used in medical research.
} 
Furthermore, Leung, Bhagat, Buchan, Erez, and Gibson (2005) argue that most of alternative culture dimensions established recently share similar concepts and correlate with Hofstede's measures. While they have been much used, Hofstede's measures are not without their critics, for example, McSweeney (2002) and Baskerville (2003).

We form our expectations of the impact of culture on ratings by considering the characteristics that, according to the research literature, are typical of societies that score highly on a specific dimension of culture. We particularly select the characteristics of a culture that are directly mentioned in, or closely related to, the description of the rating process/criteria in S\&P RatingsDirect (2013).

\subsubsection{Power distance index (PDI)}

Countries with a high power distance index are more likely to have military dictatorships, or one-party systems of government. There is also less transparency and accountability. Political violence and change by revolution is more likely (Hofstede et al., 2010, pp. 77-79). Such features are viewed as undesirable attributes by $\mathrm{S} \& \mathrm{P}$. Thus, a high power distance score is expected to have a negative effect on ratings.

\subsubsection{Individualism versus collectivism (IDV)}

Cultures high on individualism are characterised by stronger legal rights (Litch et al., 2005) and lower tax evasion (Tsakumis et al., 2007). These are viewed as desirable attributes by S\&P. Thus, greater individualism is expected to have a positive effect on ratings. The positive association between individualism and higher levels of GNI (Hofstede et al., 2010, p. 38) also suggests higher ratings for more individualistic cultures.

\subsubsection{Masculinity versus femininity (MAS)}

The effect of masculinity and femininity on ratings is not clear. Masculine cultures have more focus on material achievement and economic growth (Hofstede et al., pp. 170-175), which 
should be a positive for ratings. However, a more aggressive masculine approach may increase opportunistic behaviour with respect to lenders (El Ghoul and Zheng, 2016), may lead to acceptance of more indebtedness, and a more combative approach in negotiations to avoid default. This would have a negative effect on ratings. On the other hand, feminine cultures may tolerate higher indebtedness to finance a more welfare-oriented society. More indebtedness is a negative for ratings, but the positive rating benefit of a welfare oriented society is high social inclusion. Feminine cultures are also more likely to negotiate to avoid conflicts over debt service, which would also be a positive for ratings.

\subsubsection{Uncertainty avoidance index (UAI)}

High UA countries tend to have less market-oriented economies and a poor payment culture. They exhibit a tendency to pay their bills more slowly, De Mooij (2004, p. 154), and collecting a bounced check tends to take longer, Hofstede et al. (2010, pp. 216-217). Tax evasion is also associated with high UA (Tsakumis et al., 2007) and outside observers perceive more corruption in these countries (Hofstede et al., p. 223). High UA societies tend to embrace intolerant political ideologies and are often associated with aggressive nationalism (Hofstede et al., 2010, pp. 229-231). They are more likely to harbour extremist minorities (Hofstede et al., p. 221).

Less market-oriented economies, poor payment culture, more tax evasion, more corruption and the risk of extremist political groups are viewed as undesirable attributes by S\&P. Thus, a higher UAI score is expected to have a negative effect on ratings.

\subsubsection{Long-term versus short-term orientation (LTO)}

Countries with a high LTO value tend to see good and bad not as fixed attributes, but rather dependent on circumstances and they place importance on networks of relationships. Such countries score higher in Bribe Payers Index than countries with a low LTO value (Hofstede 
et al., 2010, p. 246).

The long-term orientation may have both positive and negative impacts on ratings. Long-term orientation correlates positively with growth and savings rates (Hofstede et al., 2010, pp. 38, 263-265), both of which favour higher ratings, but more bribes and corruption would favour lower ratings.

\section{Methods, variables and data}

Our analysis began by modelling ratings for S\&P. In order to determine whether our findings could be obtained in another setting, we replicated the S\&P analysis using Moody's ratings. The replication was intended to both test the generalizability of the results and to help guard against $p$-hacking. ${ }^{6}$ The current $\mathrm{S} \& \mathrm{P}$ study was preceded by analysis on a smaller $\mathrm{S} \& \mathrm{P}$ sample, where alternative models and estimation techniques were examined. ${ }^{7}$ Even though the current S\&P study uses a larger sample, which is drawn from a longer timeframe, the current models are based on the earlier modelling and therefore might capitalise on chance. In addition to $p$-hacking other common methodological concerns are reverse causality and omitted variables. Reverse causality is unlikely to be a concern, as culture is very stable and only changes very slowly, over many decades or centuries, Hofstede (2001), Williamson (2000). It is extremely unlikely therefore that culture will change in response to a sovereign rating. With respect to omitted variables, we include in our initial models and in robustness testing a range of variables that prior studies have shown to be significant in modelling

\footnotetext{
${ }^{6}$ The term $p$-hacking is used across a range of scientific research to describe both subconscious and conscious manipulation of data, methods and particularly the use of multiple testing to obtain a "statistically significant" result. The relevance of p-hacking to finance was highlighted by Campbell Harvey's 2017 presidential address to the American Finance Association.

${ }^{7}$ For example, we tried dummy variables for culture with break-points either based on medians or means, which made little difference to the results. We also used estimation techniques with no control for dependence among observations of the same countries. This examination of alternative models and estimation techniques was not a search for significance ( $p$-hacking) as culture variables were significant across all the models that were examined.
} 
ratings and rating changes. We also control for omitted variables and sources of endogeneity in general by undertaking additional analysis using instrumental variables.

\subsection{Rating levels}

In analysing the level of sovereign ratings, we use ordered probit to model the probability of being in a particular rating grade. This has been popular as a method for modelling sovereign ratings following $\mathrm{Hu}$, Kiesel and Perraudin (2002). The ordered probit model assumes that the rating process is governed by an unobserved latent variable $y_{i}^{*}$ for each rating observation $i$, such that:

$y_{i}^{*}=\beta_{1} P D I+\beta_{2} I D V+\beta_{3} M A S+\beta_{4} U A I+\beta_{5} L T O+\beta_{6} d u m m y_{-}$prior_default

$+\beta_{7}$ dummy_OECD_member $+\beta_{8} G D P_{-}$per_capita $+\beta_{9} G D P P_{-}$growth

$+\beta_{10}$ Square_of_GDP_growth $+\beta_{11}$ Inflation $+\beta_{12}$ Current account surplus / GDP

$+\beta_{13}$ dummy ${ }_{-}$freedom $+\beta_{14}$ Std dev of world stock market index $+\varepsilon_{i}$

Where, independent variables are defined as in Panel A of Table 2, and $\varepsilon_{i}$ is the error term.

The observable rating states, $y_{i}$, are related to the latent variable by a series of limits $z_{n}$ (to be estimated) such that:

$$
y_{i}=\left[\begin{array}{l}
1 \text { if } y_{i}^{*} \leq z_{0} \\
n \text { if } z_{n-1}<y_{i}^{*} \leq z_{n} \\
n+1 \text { if } z_{n}<y_{i}^{*}
\end{array}\right]
$$

The ratings for a sovereign nation over time represent a set of repeated measures, thus there is a need to control for dependence in the sequence of ratings. We therefore estimate the ordered probit model using the technique of Generalised Estimating Equations (GEE). The advantage of GEE is not only controlling for dependence, but also as a semi-parametric technique it is more robust than parametric alternatives.

We use all 21 rating notches for the modelling of rating levels. Table 1 gives the distribution of observations across the 21 rating notches and the numerical code for each rating notch. If the rating of a country changes in a year, we create an additional observation for the new rating. 


\section{TABLE 1 ABOUT HERE}

The independent variables for the ordered probit analysis are given in Panel A of Table 2. The table provides variable labels, variable definitions, expected signs and sources of data. All variables have been selected based on a review of the literature. References to the relevant studies that have used each variable are provided in Table 2. The first group of independent variables are the dimensions of culture as discussed above. In the empirical work we use both numeric scores for the culture variables and dummy variables. For the dummy variables scores greater than or equal to the mean score for a dimension of culture take a value of one and otherwise zero. The cultural variables have constant values over the period of the study consistent with the stability of cultures.

The rest of the variables in Table 2 Panel A are the control variables, covering the country's history of prior defaults and macroeconomic and financial variables used to model ratings. Hill et al. (2010) suggest the need to account for non-linearities by including a squared term for the GDP growth. Accordingly, we also include this squared variable in our analysis. Most of the control variables are updated annually, consistent with the frequency of data availability. However, the standard deviation of the world stock market, OECD membership, and the existence of a prior default were updated more frequently. If a rating changed during a year these three variables were updated for the new rating.

Notable omissions from the control variables are international indebtedness and the government surplus/deficit. This is because missing data on these variables would have resulted in a very greatly reduced sample size. The sample for S\&P's (Moody's) ratings would be reduced from 1764 (1606) observations to 422 (344). Including these two variables in robustness tests we find that they have little effect on the analysis.

\section{TABLE 2 ABOUT HERE}




\subsection{Rating changes}

When is a rating change likely to occur? The duration of a rating grade depends upon the hazard of a rating change. We apply the premier hazard model, Cox's hazard model (Cox, 1972), which has been used both for analysing sovereign rating migrations as in Hill et al. (2010) and for analysing corporate rating migrations as in Dang and Partington (2014) and Dang (2018). Our use of the Cox's model is additionally motivated by its convenience in handling censored observations, time-varying variables and multiple rating changes. Properly accounting for repeated events is important to the analysis of sovereign ratings as multiple rating changes of a country are common. In this study, the median number of rating changes across countries was five.

Given the presence of multiple rating changes we need to control for heterogeneity in the underlying hazard of a rating change. Hosmer, Lemeshow, and May (2008) also raises the issue of sequencing repeated events. That is, a country should not be considered at risk of a later rating change, say the fifth change, before the earlier changes, say the fourth change has occurred. Similar to Dang and Partington (2014) and Dang (2018), we estimate Cox's hazard models with stratification, so that rating changes that have the same number of prior changes are grouped in the same strata. The stratification technique allows the underlying hazard of a rating change to vary according to the number of prior changes and it also ensures that rating changes are not considered out of sequence.

The hazard of a rating change for a country in stratum $s$ can be derived from the underlying (baseline) hazard for the stratum and the country's risk factors (covariates). ${ }^{8}$ The hazard can be estimated as follows:

$$
h_{s}\left(t, X_{t}\right)=h_{s, 0}(t) \exp \left(\boldsymbol{\beta} \boldsymbol{X}_{\boldsymbol{t}}\right)
$$

\footnotetext{
${ }^{8}$ The survival probability can be estimated from the hazard.
} 
Where $h_{s}\left(t, X_{t}\right)$ is the hazard of a rating change for a rating in stratum $s$ at time $t$, with a given set of values for the covariates $X_{t}, h_{s, 0}(t)$ is the baseline hazard for stratum $s$ at time $t, \boldsymbol{\beta}$ is a vector of coefficients to be estimated and $\boldsymbol{X}_{\boldsymbol{t}}$ is a vector of covariates as defined in Panel B, Table 2.

The stratified Cox's hazard model can be estimated by multiplying together the individual likelihood functions for all the strata, and then maximizing the resulting product. ${ }^{9}$

We measure the duration of a rating from the time a rating is assigned to a country until the time the rating is changed by one notch or is censored..$^{10}$ The distribution of rating durations is given in Figure 1. We use 21 numerical codes to index the rating notches as in Table 1. The distribution of observations across the 21 rating notches is also given in Table 1.

As in Dang (2018), the covariates that we use are of two types, time-varying and time-fixed. Rating outlook and rating age are time varying and their values are updated over the duration of a rating whenever an outlook changes or a migration of interest occurs in the sample. The values of time-fixed variables are recorded at the start of a rating and remain unchanged over the duration of a rating. Concerns that the values of these variables may become stale over time are mitigated as the duration of ratings in most cases was quite short (see Figure 1). Consequently, in most cases, there was limited time for substantial changes in the magnitude of the variables treated as time-fixed. ${ }^{11}$

\footnotetext{
${ }^{9}$ For the benefit of readers unfamiliar with Cox's hazard model we should explain that the estimation of the model is based on event time and risk sets. A risk set is the set of sovereign nations at risk of a rating regrade as at the time when one of the nations is regraded. In the Cox's model the sovereign nations are subject to an underlying hazard of a rating change that can vary through time and this underlying hazard is scaled up or down according to the risk factors for each nation. A useful introduction to the Cox's hazard model can be found in Allison (1995).

${ }^{10}$ Censored rating durations arise where the latest rating has not changed by the end of the study or, as subsequently discussed, because of competing risks.

${ }^{11}$ In the preliminary study we repeated our analysis taking the measurement of the time-fixed variables at the latest possible observation date prior to the rating change. There was only a small impact on the magnitude and significance of the estimated coefficients.
} 
The covariates for the Cox's hazard model are given in Panel B of Table 2. The first group of variables are again the dimensions of culture. The second group of variables control for the current rating, for rating history and for the time-varying rating outlook. All these variables have been previously used in either, or both, of modelling corporate and sovereign rating changes (see references in Table 2). The third group of control variables represent macroeconomic and financial conditions. Most of these variables are changes in the same macroeconomic variables as used in the probit analysis and have been previously used to analyse rating levels or changes. We include a debt crisis variable as Ferri, Lui and Stiglitz (1999) suggest that sovereign rating changes are pro-cyclical, although Mora (2006) disputes this view. Roychoudhury and Lawson (2010) find that economic freedom contributes to higher ratings, we take a slightly different tack and include a control for the impact of political freedom on rating changes. ${ }^{12}$

Prior empirical evidence shows that upgrades and downgrades are governed by different models (Dang and Partington, 2014; Dang, 2018). Thus, we develop separate stratified hazard models for rating upgrades and rating downgrades. The estimation approach considers upgrades and downgrades competing risks. That is, if a country is currently rated, say BB, then an upgrade removes the country from the risk of a downgrade from the BB rating. Under the competing risks approach an upgrade is treated as censored when estimating the downgrade model and vice versa.

\subsection{Data}

The study utilises S\&P's sovereign ratings from February 1975 to June 2013 covering 77 countries. We replicate the S\&P study using Moody's data from April 1974 to June 2013

\footnotetext{
12 The variable dummy freedom is derived from political rights and civil liberties scores provided by Freedom House (2013). Civil liberties captures religion, legal system, rule of law, and economic freedom.
} 
covering 72 countries. ${ }^{13}$ The samples for S\&P's and Moody's ratings include 1764 and 1606 observations respectively. For the ordered probit analysis ratings are identified by year in order to match them to the annual economic data, but if the rating changes during the year the rating is updated, and an additional observation is added to the sample. With some exceptions, the economic data used in the ordered probit model is taken from the year prior to the start of a rating. As in Hill et al. (2010), GDP growth, square of GDP growth, inflation, current account surplus/GDP are constructed as the geometric average of the previous three-year annual rates. The standard deviation of the world stock market index (Std dev of world stock market index) is calculated using daily data over a six-month rolling window prior to the rating observation under study. Dummy OECD member and dummy prior default are updated at the time a country is assigned a rating.

For the Cox's hazard model we observe ratings at the level of individual notches and measure the duration of the rating in each notch observed for each country. We also observe whether the rating is subsequently upgraded or downgraded and the sequence number in the rating changes for each country. Requiring data for the control variables, including rating history and rating outlook, restricted the sample size for S\&P to 382 rating durations from 70 countries. There were 149 downgrades, 165 upgrades, and 68 censored cases. For Moody's, the sample size was 303 rating durations from 62 countries. There were 106 downgrades, 135 upgrades and 62 censored cases.

The details of the data sources for the independent variables in the ordered probit analysis and the Cox's hazard analysis are given in Table 2. The measurements of the culture variables across countries were obtained from a website maintained by Hofstede ${ }^{14}$ which provides the

\footnotetext{
${ }^{13}$ The study periods were dictated by the ratings and macro-economic data available to us. Since we wanted to conduct the Moody's and the S\&P study over the same period we were constrained to a 2013 end date by our access to Moody's data, although we had S\&P rating data to 2017.

${ }^{14}$ See dimension-data-matrix in http://www.geerthofstede.nl
} 
measurements from Hofstede et al. (2010) in spreadsheet format. Table 3 gives the descriptive statistics for the numeric scores on the five dimensions of culture across the different samples used in the study. The scores for each of the culture dimensions vary markedly across countries but the distributions of the culture variables show considerable similarity across all four samples in Table 3.

\section{TABLE 3 ABOUT HERE}

\section{Results}

\subsection{Rating levels}

The results of the ordered probit models for rating levels are given in Table 4 . The expected sign of a culture variable coefficient is given in parentheses next to the variable label and the significant coefficients are in bold. For each of the rating agencies two sets of results are given, first using numeric scores for the dimensions of culture, second using culture dummies. The QIC statistic, given at the foot of Table 4, provides a basis for comparing the models, with lower QIC statistics indicating more explanatory power. The QIC statistics show that the models with culture variables perform better than the models without culture variables.

\section{TABLE 4 ABOUT HERE}

The signs of the coefficients for the culture variables are the same across all the four models, but there are differences in statistical significance. The positive sign on individualism and the negative sign on uncertainty avoidance index are consistent with expectations, but not the positive sign on power distance index. We had no particular expectations for the sign on longterm orientation and masculinity, which have positive and negative signs respectively. Individualism and the uncertainty avoidance index are significant across both models for S\&P and across both models for Moody's ratings. A long-term orientation is significant in both models for S\&P and one model for Moody's ratings. The power distance index and masculinity achieve significance in two out of the four estimated models. 
All the control variables, except for dummy freedom and current account surplus/GDP have at least one significant coefficient. However, not all control variables are consistently significant between the models for S\&P and Moody's ratings. For the consistently significant control variables (dummy prior default, GDP per capita, GDP growth, square of GDP growth, and inflation) the signs of the coefficients are in accord with prior research.

\subsection{Rating changes}

The distribution of survival times (durations) for S\&P and Moody's rating changes are given in Figure 1. For S\&P (Moody's) ratings, the mean durations are 1.83 (1.92) years for downgrades and 2.45 (2.91) years for upgrades. It is evident from Figure 1 that a majority of ratings tend to be quite short lived. Most downgrades have durations of 6 months or less and most upgrades have durations of 1.5 years or less.

\section{FIGURE 1 ABOUT HERE}

The results for the estimation of the stratified Cox's hazard model are given in Table 5 (S\&P) and Table 6 (Moody's). Using the numeric culture scores and the culture dummies, two models are estimated for downgrades and two models for upgrades. The likelihood ratio chi squares, given at the foot of Table 5 and Table 6 , show that the inclusion of culture variables significantly improves the explanatory power of the model. In all case the improvement is significant at the 0.01 level or better.

\section{TABLES 5 AND 6 ABOUT HERE}

For the S\&P results (Table 5) only three dimensions of culture are significant. Individualism is significant in three of the four models examined and has a consistent effect. The change from a collective to an individualistic culture decreases the risk of a downgrade by $55 \%$ and increases the chance of an upgrade by $69 \% .{ }^{15}$ Long-term orientation and power distance only

\footnotetext{
15 The change in risk for a one-unit change in an independent variable can be calculated by subtracting one from hazard ratio. Thus a hazard ratio of 3 represents a twofold, or 200 percent increase in risk, while a hazard ratio of
} 
achieve significance in one model, increasing the chance of an upgrade and reducing the risk of a downgrade respectively.

For Moody's downgrades (Table 6), high power distance, individualism and a long-term orientation significantly reduce the risk of a downgrade, by $42 \%, 69 \%$ and $35 \%$ respectively. However, only the effect of a long-term orientation is significant for both numeric score and dummy variable specifications of the downgrade models. The chance of an upgrade increases with a higher power distance but is only significant when culture is measured as a numeric score.

The results for the control variables in Tables 5 and 6 confirm the results from the prior literature, that outlook and rating momentum (dummy lag one downgrade) are important in explaining sovereign rating changes, Alsakka and ap Gwilym (2009) and Hill et al. (2010). For both S\&P and Moody's, a negative (positive) outlook virtually eliminates the risk of an upgrade (downgrade) and increases the risk of a downgrade (upgrade) by over $300 \%$ (400\%). With respect to momentum, a downgrade at lag one rating increases the chance of a further downgrade by over $60 \%$ for S\&P and over $300 \%$ for Moody's. A downgrade at lag one also reduces the risk of an upgrade by over $50 \%$ for $\mathrm{S} \& \mathrm{P}$ but has no significant effect for Moody's.

Many of the economic control variables are either not statistically significant or have a relatively small effect on the hazard of a rating change. Notable exceptions are the debt crisis variable (Dummy debt crisis) and OECD membership (Dummy OECD member). During debt crises the risk of a downgrade increases by more than $160 \%$ for S\&P ratings, which is consistent with procyclical ratings (Ferri, Lui and Stiglitz, 1999). The debt crises variable is 
not significant for Moody's ratings. However, the very strong momentum effect for Moody's, as shown above, would intensify the incidence of downgrades during debt crises.

\subsection{Robustness}

\section{a. Control variables}

The replication using Moody's ratings is one source of confidence about the robustness of culture in explaining sovereign ratings and rating changes. We also note that when substituting time-varying CreditWatch (Watchlist) for time-varying outlook in the Cox's model for S\&P (Moody’s) ratings culture remains a significant determinant of rating changes. We also undertook additional analysis based on the samples including data for international indebtedness and the government surplus/deficit. These variables were originally excluded because missing data resulted in greatly reduced sample sizes (422 observations for S\&P and 344 observations for Moody's). Estimating an ordered probit model fitting 21 rating notches and 16 variables (including international indebtedness and the government surplus/deficit) would result in very low statistical power. Therefore, we followed the approach that Hill et al. (2010) used to recode the 21 rating classes into eight rating grades. The four ordered probit models in Table 4 were then re-estimated with the addition of both international indebtedness and the government surplus/deficit variables. Next the analysis was repeated on exactly the same samples but excluding the variables for international indebtedness and the government surplus/deficit.

The exclusion of these two variables had no impact on the sign of the coefficients for the culture variables and had very little impact on their magnitude. Except for individualism/ dummy_IDV, there was no change in the culture variables that were significant. Individualism/ dummy_IDV was significant in three of the four models that included international indebtedness and the government surplus/deficit, but not in the model for S\&P ratings where 
culture was measured by dummy variables. Whereas, after dropping these two variables, individualism/dummy_IDV had a significant positive effect on ratings in all four models.

\section{b. Different proxies for culture}

To test whether our findings are sensitive to culture proxies, we employ two culture traits hierarchy and embeddedness established by Schwartz (1994) as alternatives for Hofstede's measures. We chose these two measures of culture because they have significant correlations with individual measures employed by Hofstede (Hofstede et al., 2010, p. 41). Hierarchy is substituted for the power distance index $(P D I)$ and embeddedness is substituted for individualism $(I D V)$ but is expected to have the opposite sign. ${ }^{16}$ The ordered probit model is thus re-estimated using a sample of $1481 \mathrm{~S} \& \mathrm{P}$ ratings with no missing values for $M A S, U A I$, LTO, hierarchy and embeddedness.

Untabulated results of the re-estimation are generally consistent with the results of the original S\&P probit model in Table 4 (column 2). There was a significant negative effect for embeddedness, consistent with the prior significant positive effect of $I D V$. The culture variables of MAS, UAI, LTO are also significant and have the same sign as in the main results. However, hierarchy, which is substituted for $P D I$, is no longer significant.

\subsection{Endogeneity of culture}

Our modelling of rating levels may suffer from potential endogeneity. As discussed earlier, reverse causality is unlikely as culture is extremely stable. The main source of endogeneity, if any, might be omitted variables. ${ }^{17}$

\footnotetext{
${ }^{16}$ Embeddedness is closely related to collectivism and hence is the opposite of individualism (IDV).

17 The classic problem of endogeneity, correlation between the independent variables and the error term, does not apply in our modelling of rating changes because the Cox model has no error term. However, missing variables can still be a problem. This is mitigated by including variables well known to predict rating changes and which capture the views of rating analysts as expressed in the time-varying CreditWatch and time-varying outlook. We also include lagged rating downgrade which is a key determinant of sovereign rating changes (Hill et al., 2010; Alsakka and ap Gwilym, 2012) and we also include the current rating in the Cox's hazard model.
} 
We address the problem of omitted variables in several ways. First, we employ an extensive set of the key determinants of ratings as identified by the literature. Second, we test the robustness of the result to more controls (international indebtedness and the government surplus/deficit), albeit with a reduced sample size, as discussed earlier. Third, we employ the instrumental variable (IV) method. Our instrument variables are identified from previous studies on culture (Boubakri and Saffar, 2015; Aggarwal, Faccio, Guedhami and Kwok, 2016; El Ghoul and Zheng, 2016; Berger et al., 2018; Figlio, Giuliano, Özek, and Sapienza, forthcoming). The instruments, as discussed below, are a politeness distinction indicator ( $\left.t v \_d i f f\right)$, historical prevalence of pathogenic diseases (diseases), gender inequality, religion, and historical crop yield. Each instrument seems very unlikely to have a direct impact on rating levels over our study period and thus should satisfy the IV exclusion restriction. Each instrument has a relation with a culture dimension, as discussed below, and thus the instruments satisfy the IV relevance requirement.

We employ a politeness distinction index namely tu-vos differentiation ( $t v \_$diff), which captures the share of a country's population that speaks a language with various secondperson singular pronouns, as the instrument for power distance index (PDI). The tu-vos differentiation indicator was created by Davis and Abdurazokzoda (2016) and is named after the Latin $t u$ and vos. People who speak languages with various second-person singular pronouns, for example, French (with informal tu and formal vous) or German (with informal $d u$ and formal Sie), are more conscious of status and social distances than those from other languages (Kashima and Kashima, 1998). This indicator reflects a strong emphasis on social status and hierarchy and thus, this implies a positive relation between $t v \_d i f f$ and PDI.

To instrument for individualism (IDV) we use an index which captures the historical prevalence of nine infectious diseases in 230 different regions (diseases). Murray and Schaller (2010) created this index using the data before the epidemiological revolution in treating 
pathogenic diseases. According to Fincher, Thornhill, Murray, and Schaller (2008), people from collectivistic societies are more cautious in contacting with strangers and are less likely to try exotic food. Collectivism performs as an anti-pathogen defence mechanism, and it is more likely associated with countries that have historically suffered from higher levels of pathogens. A positive association between the historical prevalence of diseases and collectivism implies a negative association with individualism (IDV).

We employ gender inequality to instrument for masculinity (MAS). The data on gender inequality is for 1990 and comes from the IMF. ${ }^{18}$ Masculine countries are characterised by a strong division of gender roles, and gender inequality tends to occur more often in these countries (Hofstede et al., 2010; Berger et al., 2018). This implies a positive relation between gender inequality and MAS.

To instrument for uncertainty avoidance index (UAI) we use religion, measured as the difference between the fractions of the Catholic and Protestant populations (catholicprotestant). The percentage of a country's population classed as Catholic and Protestant in 1980 comes from La Porta, Lopez-De-Silanes, Shleifer, and Vishny (1999). Hofstede (2001) find that Catholic countries score higher, while Protestant countries score lower, on uncertainty avoidance. This implies a positive relation between Catholic minus Protestant (catholic-protestant) and UAI.

Our instrument for long-term orientation (LTO) is historical crop yield (measured in tens of millions of kilo calories, per hectare, per year). This is based on estimates of historical crop yields derived by Galor and Özak (2016). To instrument for LTO we take the logarithm of the maximum potential caloric yield attainable given the set of crops that are suitable for

\footnotetext{
18 The gender inequality data is only available from 1990. A few countries have missing gender inequality data in 1990. For these countries we use the average of the data available over the period 1991-2012. This maintains a sample with the same number of countries as in the main analysis.
} 
cultivation in the pre-1500 period. Galor and Özak find that people whose ancestors enjoyed higher crop yields exhibit long-term oriented behaviour today. This implies a positive relation between historical crop yield and LTO.

Since the dependent variable for the ordered probit model is a set of ranking states, the twostage residual inclusion method (control function approach) ${ }^{19}$ is the appropriate way to address endogeneity (Wooldridge, 2015). In the first stage we regress Hofstede's numeric culture values against the instrumental variables and control variable and compute the residuals. The second stage equation is estimated using ordered probit and contains the original culture and control variables plus the fitted residuals. Bootstrapping is used to estimate the standard errors.

The key results of the two-stage residual inclusion (2SRI) procedure are reported in Table 7. Columns (2) to (6) include the results of the first-stage OLS regressions. Columns (7) and (8) give the results for the ordered probit models estimated by maximum likelihood. Colum (7) includes the results (coefficients and standard errors) of the second-stage ordered probit (endogeneity corrected) model. Column (8) includes the results (coefficients and standard errors) of endogeneity-uncorrected ordered probit model, and the coefficients exactly match those as taken from column (2) in Table 4. Significant culture variables in columns (7) and (8) are in bold.

\section{TABLE 7 ABOUT HERE}

The relation between each instrumental variable ( $t v \_$diff, diseases, gender inequality, religion, historical crop yield) and its respective endogenous variable (PDI, IDV, MAS, UAI, LTO) has a sign consistent with the discussion above, but in the case of gender inequality its effect on MAS is not significant ( $p$ value $=12.8 \%$ ), although it is significantly related to LTO. Adding

\footnotetext{
${ }^{19}$ The inclusion of the fitted residuals has the effect of controlling for omitted variables, hence the alternative label of the control function approach.
} 
the instrumental variables to a model containing only the control variables improves the $\mathrm{R}^{2}$ of all five first-stage regressions. The F-statistics for the test of the joint significance of the coefficients of the five instruments in the first-stage regressions are significant at the $1 \%$ level for all five regressions, confirming the explanatory power of the instruments.

The effect of the instruments for culture on the probability of a higher rating level are given in column 7. The five fitted residuals added to the second-stage regression are significant (column 7), which indicates endogeneity in the results of the uncorrected ordered probit model. All culture variables are significant (column 7, in bold) and have larger absolute values for the coefficients relative to the original model (column 8). Except for MAS, the signs of the coefficients of other culture variables (column 7) are consistent with their signs in the uncorrected ordered probit model (column 8). Thus, after controlling for endogeneity we continue to find statistically significant effects of culture on rating levels. Two culture dimensions, $I D V$ and $L T O$, give consistently significant results across the original results, robustness tests and the two-stage analysis. ${ }^{20}$ The significant effect of individualism is in harmony with the remark of Aggarwal et al. (2016, p. 467) that Hofstede's individualism trait is often found to be "a particularly strong predictor of a variety of outcomes".

\section{Conclusion}

We argue that national culture may affect both the level of a sovereign rating and the risk that it will change. To empirically test these propositions, we utilized Hofstede's five dimensions of national culture in models of sovereign rating levels and sovereign rating changes. In

\footnotetext{
${ }^{20}$ An untabulated analysis of the marginal effects of culture variables finds that the change in the probability that rating level being the median rating $(14$ or $\mathrm{BBB}+$ ) for a one unit change in IDV and LTO (other predictors are set at their mean values) is respectively $-.0227 \%$ and $-.0219 \%$. Without accounting for endogeneity, the change in that probability for a one unit change in IDV and LTO (other predictors are set at their mean values) is $-.0185 \%$ and $-.018 \%$ respectively (untabulated). The changes in probabilities are relatively small but so is a one unit change in a culture measurement.
} 
undertaking the modeling, we include control variables identified as relevant to sovereign ratings in the prior literature. The controls are important to the interpretation of the results. This is because national culture may affect both economic performance and previous rating history, both of which directly affect ratings and rating changes. Because we control for these variables, the results of culture that we report reflect the additional explanatory power of culture after controlling for current economic performance and rating history. The results show that culture is significant in explaining both levels of sovereign ratings and changes in those ratings. Including culture variables results in an improvement in the power of the models relative to models excluding culture.

For sovereign rating levels there was evidence of statistical significance for all five of the culture dimensions, but they were not all consistently significant across the models estimated. Overall, individualism, uncertainty avoidance and a long-term orientation were the most consistently significant variables for both S\&P and Moody's rating levels. The positive effects of individualism and a long-term orientation and the negative effect of uncertainty avoidance on achieving higher rating levels were also robust to the use of instrumental variables for culture. For rating changes the only significant culture variables were individualism, a long-term orientation and the power distance index. These variables were significant for both S\&P and Moody's but their significance varied between models for upgrades and downgrades.

Knowing the nature of a country's culture can help explain the sovereign rating grade it receives. Culture is a fundamental determinant of the way governments and societies behave; therefore, it is not so surprising to find that culture affects sovereign ratings and in turn affects sovereign rating regrades. Culture only changes slowly, the economic consequence of this for ratings is that over long periods some countries are naturally predisposed towards lower ratings, while others are naturally predisposed towards higher ratings. Similarly, over long 
periods some countries are naturally predisposed to experience rating changes in a particular direction. These effects are substantive, for example with respect to rating changes a shift from collectivism to individualism increases the chance of an S\&P's rating upgrade by $69 \%$ and lower the risk of an S\&P's rating downgrade by $55 \%$.

With respect to the debate about the cyclicality of ratings our results support procyclicality as argued by Ferri, Lui and Stiglitz (1999). The combination of procyclical ratings and the stability of culture suggests that knowledge of culture can be helpful in the management of international bond portfolios. For example, tilting the portfolio towards countries with an individualistic culture will help reduce losses from rating downgrades. This is particularly so during global economic downturns when, due to procyclicality, the number of downgrades accelerates.

Our results also have some relevance to regulatory reforms in relation to the rating industry. An early strand of this reform has been to require increased disclosure in order to improve the transparency of the rating process. A later strand of reform has attempted to diminish the extent to which institutional investors rely on ratings as opposed to making their own judgements on credit worthiness. In respect to disclosure, our results suggest that rating agencies should disclose if and how they utilise culture and/or culture related variables in their sovereign rating process. In relation to institutional investors relying more on their own judgements, our results suggest that culture is a factor to consider when making judgements in respect to ratings, sovereign credit risk and the composition of bond portfolios. 


\section{References}

Afonso, A., 2003. Understanding the determinants of sovereign debt ratings: Evidence for the two leading agencies. Journal of Economics and Finance 27, 56-74.

Afonso, A., Gomes, P., Rother, P., 2011. Short and long-run determinants of sovereign debt credit ratings. International Journal of Finance and Economics 16, 1-15.

Aggarwal, R., Goodell, J., 2009. Markets and institutions in financial intermediation: National characteristics as determinants. Journal of Banking and Finance 33, 1770-1780.

Aggarwal, R., Faccio, M., Guedhami, O., and Kwok, C., 2016. Culture and Finance: An Introduction. Journal of Corporate Finance 41, 466-474.

Allison, P. D., Ed. 1995. Survival Analysis Using SAS: A Practical Guide. SAS Institute Inc., Cary.

Alsakka, R., ap Gwilym, O., 2009. Heterogeneity of sovereign rating migrations in emerging countries. Emerging Markets Review 10, 151-165.

Alsakka, R., ap Gwilym, O., 2010. Leads and lags in sovereign credit ratings. Journal of Banking and Finance 34, 2614-2626.

Alsakka, R., ap Gwilym, O., 2012. Rating agencies' credit signals: An analysis of sovereign watch and outlook. International Review of Financial Analysis 21, 45-55.

Altman, E., 1998. The importance and subtlety of credit rating migration. Journal of Banking and Finance 22, 1231-1247.

Ashraf, B., Zheng, C., Arshad, S., 2016. Effects of national culture on bank risk-taking behavior. Research in International Business and Finance 27, 309-326.

Bannier, C.E., Hirsch, C.W., 2010. The economic function of credit rating agencies-What does the watchlist tell us? Journal of Banking and Finance 34, 3037-3049.

Baskerville, R., 2003. Hofstede never studied culture. Accounting, Organizations and Society 28, 1-14

Berger, A. N., Xinming, L., Morris, C. S., and Roman, R. A., 2018. The Effects of Cultural Values on Bank Failures around the World (November 2018). Available at SSRN: https://ssrn.com/abstract=3023442 or http://dx.doi.org/10.2139/ssrn.3023442

Beugelsdijk, S, Maseland, R., van Hoorn, A., 2015. Are scores on Hofstede's dimensions of national culture stable over time? A cohort analysis, Global Strategy Journal 5, 223-240.

Bissoondoyal-Bheenick, E., 2005. An analysis of the determinants of sovereign ratings. Global Finance Journal 15, 251-280.

Boubakri, N., and Saffar, W. 2015. Individualism and Firm Growth. Working paper. Available at https://pdfs.semanticscholar.org/bcd1/c475743da0a46b5bca1f5db617c1640d91f7.pdf

Cantor, R., Packard, F., 1996. Determinants and impacts of sovereign credit rating. Journal of Fixed Income 2, 37-53.

Chinese Culture Connection, 1987. Chinese values and the search for culture-free dimensions of culture. Journal of Cross-Cultural Psychology 18, 143-164.

Chui, A., Lloyd, A. and Kwok, C., 2002. The determination of capital structure: is national culture a missing piece to the puzzle? Journal of International Business Studies 33, 99-127.

Chung, Y., 2007. The Relationship between Export Marketing Negotiation and National Cultures in Hofstede and Hall's Perspectives. Journal of International Area Studies 11 (1), 253-290.

Clark, E., Zenaidi, A., 1999. Sovereign debt discounts and the unwillingness to pay. Finance 20, 185 199.

Correa, R., Lee, K., Sapriza, H., Suarez, G., 2014. Sovereign credit risk, banks' government support and bank stock returns around the world. Journal of Money, Credit and Banking, Supplement to Vol. 46, 93-121.

Cox, D., 1972. Regression models and life tables. Journal of Royal Statistical Society Series B (Methodological) 34, 187-220.

Dang, H., Partington, G., 2014. Rating migrations: The effects of rating history and time. ABACUS 50, 174-202.

Dang, H.D., 2018. National Culture and Corporate Rating Migrations. Risks 6(4), 130

Davis, L.S., and Abdurazokzoda, F., 2016. Language, culture and institutions: Evidence from a new linguistic dataset. Journal of Comparative Economics 44, 541-561.

De Mooij, M., 2004. Consumer Behaviour and Culture: Consequence for Global Marketing and Advertising. Sage, Thousand Oaks. 
De Paoli, B., Hoggarth, G., Saporta, V., 2009. Output costs of sovereign crises: Some empirical estimates. Bank of England Working Paper No. 362.

Eaton, J., Gersovitz, M., Stiglitz, J., 1986. The pure theory of country risk. European Economic Review 30, 481-513.

El Ghoul, S., and Zheng, X., 2016. Trade credit provision and national culture. Journal of Corporate Finance 41, 475-501

Ferri, L., Liu, L., Stiglitz, J., 1999. The procyclical role of rating agencies: Evidence from the East Asian crisis. Economic Notes 28, 335-355.

Fidrmuc, J. P., and Jacob, M., 2010. Culture, agency costs and dividends. Journal of Comparative Economics 38, 321-39

Figlio, D., Giuliano, P., Özek, U. and Sapienza, P. Forthcoming. Long-Term Orientation and Educational Performance. American Economic Journal: Economic Policy

Fincher, CL., Thornhill, R., Murray, DR, and Schaller, M. 2008. Pathogen prevalence predicts human cross-cultural variability in individualism/collectivism. Proceedings of the Royal Society B: Biological Sciences 275(1640):1279-85

Freedom House, 2013. Freedom in the World 2013: The Annual Survey of Political Rights and Civil Liberties. Rowman \& Littlefield.

Fuchs, A., and Gehring, K., 2017. The Home Bias in Sovereign Ratings, Journal of the European Economic Association 15(6), 386-1423.

Galor, O. and Ozak, O., 2016. The Agricultural Origins of Time Preference, American Economic Review 106(10), 3064-3103

Guettler, A., Wahrenburg, M., 2007. The adjustment of credit ratings in advance of defaults. Journal of Banking and Finance 31, 751-767.

Guiso, L., Sapienza, P., and Zingales., L., 2009. Cultural biases in economic exchange? Quarterly Journal of Economics 124, 1095-1131.

Guiso, L., Herrera, H., Morelli, M., 2016. Cultural differences and institutional integration. Journal of International Economics 99, 97-113.

Harvey, C., 2017. Presidential Address: The Scientific Outlook in Financial Economics, Journal of Finance, 72, 1399-1440.

Haq, M., Hu, D., Faff, R., and Pathan, S., 2018. New evidence on national culture and bank capital structure, Pacific-Basin Finance Journal 50, 41-64.

Hill, P., Brooks, R., Faff, R., 2010. Variations in sovereign credit quality assessments across rating agencies. Journal of Banking and Finance 34, 1324-1343.

Hofstede, G., 1980. Culture's Consequences: International Differences in Work-Related Values. Sage, Beverly Hills.

Hofstede, G., 2001. Culture's Consequences: Comparing Values, Behaviors, Institutions and Organizations across Nations. Sage, Beverly Hills.

Hofstede, G., Hofstede, G., Minkov, M., 2010. Cultures and Organizations: Software of the Mind, third ed. McGraw-Hill, New York.

Hosmer, D., Lemeshow, S., May, S., 2008. Applied Survival Analysis, second ed. Wiley, New York.

Hu, Y., Kiesel, R., Perraudin, W., 2002. The estimation of transition matrices for sovereign credit ratings. Journal of Banking and Finance 26, 1383-1406.

Husted, B., 1999. Wealth culture and corruption. Journal of International Business Studies 3: 339-59.

Jordan, C., 2017. Cultural Impact: The Eurozone crisis. Retrieved from https://medium.com/@ courtneyjordan/cultural-impact-the-eurozone-crisis-4b03b2bc77bf on 30 January 2019.

Karolyi, G. A., 2016. The gravity of culture for finance. Journal of Corporate Finance 41, 610-625

Kashima, E. S., Kashima, Y., 1998. Culture and language: The case of cultural dimensions and personal pronoun use. Journal of Cross-Cultural Psychology 29, 461-486.

Kristjánsdóttir, H., Guðlaugsson, P. Ö., Guðmundsdóttir, S. and Aðalsteinsson, G. D., 2017. Hofstede national culture and international trade, Applied Economics, 49(57), 5792-5801.

Kwok, C., Tadesse, S., 2006. National culture and financial systems. Journal of International Business Studies 37, 227-247.

La Porta, R., Lopez-De-Silanes, F., Shleifer, A., Vishny, R., 1999. The quality of government. Journal of Law, Economics, and Organization 15, 222-279. 
Laeven, L., and Valencia, F., 2012. Systemic banking crises database: An update. IMF Working Paper $\mathrm{WP} / 12 / 163$.

Leung, K., Bhagat, R.S., Buchan, N.R., Erez, M., Gibson, C.B., 2005. Culture and international business: Recent advances and their implications for future research. Journal of International Business Studies 36, 357-378.

Li, K., Griffin, D., Yue, H., Zhao, L., 2013. How does culture influence corporate risk-taking? Journal of Corporate Finance 23, 1-22.

Licht, A., Goldschmidt, C., Schwartz, S., 2005. Culture, law and corporate governance. International Review of Law and Economics 25, 229-255.

Lucke, N., and Eichler, S., 2016. Foreign Direct Investment: The Role of Institutional and Cultural Determinants. Applied Economics 48 (11), 935-956.

Manasse, P., Roubini, N., Schimmelpfennig, A., 2003. Predicting sovereign debt crisis. IMF Working Paper 03/221.

Maridal, J. H., 2013. Cultural impact on national economic growth. Journal of Socio-Economics 47, 136-146.

McSweeney, B., 2002. Hofstede's model of national cultural differences and their consequences: A triumph of faith, a failure of analysis. Human Relations. 55, 89-118.

Mora, N., 2006. Sovereign credit ratings: Guilty beyond reasonable doubt? Journal of Banking and Finance 30, 2041-2062.

Murray, D.R., Schaller, M., 2010. Historical prevalence of infectious diseases within 230 geopolitical regions: A tool for investigating origins of culture. Journal of Cross-Cultural Psychology 41, 99-108.

Nakata, C., Sivakumar, K., 1996. National culture and new product development: An integrative review. Journal of Marketing 60, 61-72.

Reusens, P, and Croux, C., 2017. Sovereign credit rating determinants: A comparison before and after the European debt crisis. Journal of Banking and Finance 77, pp. 108-121.

Roychoudhury, S., Lawson, A., 2010. Economic freedom and sovereign credit ratings and default risk. Journal of Financial Economic Policy 2, 149-162.

Schwartz, S.H. 1994. Beyond Individualism-Collectivism: New Dimensions of Values. In U. Kim, H.C. Triandis, C. Kagitcibasi, S.-C. Choi, and G. Yoon, eds., Individualism and Collectivism: Theory, Method and Application. Newbury Park, CA: Sage.

S\&P Global Ratings' Credit Research, 2013. Default Study: Sovereign Defaults and Rating Transition Data, 2012 Update.

S\&P RatingsDirect, 2009. Use of CreditWatch and Outlooks (14 September 2009).

S\&P RatingsDirect, 2013. Sovereign Government Rating Methodology and Assumptions.

Stulz, R., Williamson, R., 2003. Culture, openness and finance. Journal of Financial Economics 70, 313-349.

Tajaddini, R., and Gholipour, H. F. 2017. National Culture and Default on Mortgages. International Review of Finance 17, 107-133

Tsakumis, G. T., Curatola, A. P., Porcano, T. M., 2007. The relation between national cultural dimensions and tax evasion. Journal of International Accounting, Auditing and Taxation 16, $131-$ 147.

Vazza, D., Aurora, D., Schneck, R., 2005. Crossover Credit: A 24-year Study of Fallen Angel Rating Behaviour. Global Fixed Income Research. Standard and Poor's, New York.

Vazza, D., Leung, E., Alsati, M., Katz, M., 2005. CreditWatch and ratings outlooks: Valuable predictors of rating behaviour. Global Fixed Income Research. Standard and Poor's, New York.

Weaver, G. R., 2001. Ethics programs in global businesses: Culture's role in managing ethics. Journal of Business Ethics 30, 3-15.

Williamson, O., 2000. The new institutional economics: taking stock and looking ahead, Journal of Economic Literature, 38, 595-613.

Wooldridge, J. M., 2015. Control function methods in applied econometrics. Journal of Human Resources, 50(2), 420-445. 
Table 1 Distribution and coding of ratings

\begin{tabular}{lccccc}
\hline $\begin{array}{l}\text { S\&P's } \\
\text { (Moody's) }\end{array}$ & $\begin{array}{c}\text { Numerical } \\
\text { rating } \\
\text { coding }\end{array}$ & $\begin{array}{c}\text { S\&P's sample } \\
\text { for probit model }\end{array}$ & $\begin{array}{c}\text { Moody's sample } \\
\text { for probit model }\end{array}$ & $\begin{array}{c}\text { S\&P's } \\
\text { sample for } \\
\text { Cox model }\end{array}$ & $\begin{array}{c}\text { Moody's } \\
\text { sample for } \\
\text { Cox model }\end{array}$ \\
\hline AAA (Aaa) & 21 & 312 & 328 & 8 & 12 \\
AA+ (Aa1) & 20 & 97 & 75 & 16 & 16 \\
AA (Aa2) & 19 & 83 & 100 & 13 & 13 \\
AA- (Aa3) & 18 & 64 & 57 & 18 & 15 \\
A+ (A1) & 17 & 64 & 102 & 17 & 19 \\
A (A2) & 16 & 124 & 98 & 24 & 22 \\
A- (A3) & 15 & 112 & 87 & 25 & 23 \\
BBB+ (Baa1) & 14 & 84 & 106 & 28 & 22 \\
BBB (Baa2) & 13 & 124 & 50 & 30 & 15 \\
BBB- (Baa3) & 12 & 135 & 152 & 32 & 25 \\
BB+ (Ba1) & 11 & 119 & 118 & 29 & 25 \\
BB (Ba2) & 10 & 107 & 63 & 25 & 18 \\
BB- (Ba3) & 9 & 93 & 73 & 23 & 16 \\
B+ (B1) & 8 & 93 & 67 & 26 & 23 \\
B (B2) & 7 & 72 & 62 & 25 & 17 \\
B- (B3) & 6 & 47 & 45 & 21 & 11 \\
CCC+ (Caa1) & 5 & 14 & 15 & 8 & 7 \\
CCC (Caa2) & 4 & 11 & 0 & 8 & 0 \\
CCC- (Caa3) & 3 & 3 & 1 & 2 & 1 \\
CC (Ca) & 2 & 6 & 5 & 4 & 2 \\
C (C) & 1 & 0 & 2 & 0 & 1 \\
\hline Total observations & & 1764 & 1606 & 382 & 303 \\
\hline
\end{tabular}

This table shows the distribution of observations over rating grades and the conversion of S\&P's and Moody's alphabetic grades to numerical scores for the probit regression and for the Cox regression. 
Table 2 Definition of variables used in the analysis

\section{Panel A: Variables for the ordered probit analysis of rating levels}

\section{National culture dimensions Source: Hofstede et al. (2010)}

Power distance index

(PDI/ -ve)

Individualism (IDV/ +ve)

vs. collectivism

Masculinity (MAS/ ?) vs femininity

Uncertainty avoidance index

(UAI/ -ve)

Long-term (LT/ ?) vs. short-term (ST) orientation

In large PD cultures "organisations centralise power as much as possible in a few hands." Inequalities are accepted without questions (Hofstede et al., 2010, p. 73)

A country's position on this dimension is reflected in whether people's self-image is defined in terms of "I" (individualism) or "we" (collectivism).

Countries with a masculine orientation favour a performance and competitive society (Hofstede et al., 2010). Countries with feminine orientation "emphasize human needs, care and interdependence, even at the expense of accomplishment and performance" (Weaver, 2001, p. 9)

The uncertainty avoidance index reflects the degree to which a country may embrace uncertainty and ambiguity with ease and comfort.

Long-term (short-term) oriented cultures are oriented towards the future (the present). People in LT countries show perseverance and thrift, and they prioritise future benefit over current benefit (Hofstede et al., 2010, p. 239).
Licht et al. (2005), Fidrmuc and Jacob (2010), Ashraf et al. (2016), Dang (2018), Haq et al. (2018), Berger et al. (2018)

Licht et al. (2005), Tsakumis et al. (2007), Fidrmuc and Jacob (2010), Li et al. (2013), Boubakri and Saffar (2015), Ashraf et al. (2016), Tajaddini and Gholipour (2017), Haq et al. (2018), Dang (2018), Berger et al. (2018)

Licht et al. (2005), El Ghoul and Zheng (2016), Dang (2018), Haq et al. (2018), Berger et al. (2018)

Licht et al. (2005), Kwok and Tadesse (2006), Tsakumis et al. (2007), Aggarwal and Goodell (2009), Fidrmuc and Jacob (2010), Li et al. (2013), Ashraf et al. (2016), Dang (2018), Haq et al. (2018), Berger et al. (2018)

Hofstede et al. (2010), Dang (2018), Haq et al. (2018), Figlio et al (forthcoming)

Default history Source: S\&P Global Ratings' Credit Research (2013)

Dummy prior default (-ve) The dummy takes the value of one if a country experienced a foreign currency-

Cantor and Packard (1996), Hu, Kiesel, Perraudin (2002), denominated debt default prior to the rating under study, and zero otherwise

Afonso (2003), Mora (2006), Hill et al (2010), Dang (2018)

Macroeconomic and financial variables Source: World Bank databases unless otherwise stated

Dummy OECD member

(+ve)

GDP growth (+ve)

GDP per capita (+ve)

Inflation (-ve)

Current account surplus or

deficit to GDP (+ve)
This variable takes a value of one if a country is a member of the OECD at the start of the rating being analysed, and zero otherwise.

The geometric average of the previous three-year annual growth rate in GDP

GDP in constant (US\$ 2005) prices divided by mid-year population

The geometric average of the previous three-year inflation as measured by the consumer price index.

The geometric average of the previous three-year current account surplus or deficit divided by GDP defined as above.
Ferri, Lui and Stiglitz (1999), Mora (2006), Dang (2018)

Cantor and Packard (1996), Ferri et al. (1999), Mora

(2006), Hill et al. (2010), Afonso et al. (2011), Reusens and Croux (2017), Dang (2018)

Hill et al. (2010) 
Std dev of world stock market index (-ve) Square of GDP growth $(-1-20$
The annualised standard deviation of the Datastream world stock market index, which is Hill et al. (2010) calculated using daily data over a six-month rolling window prior to the rating under study

Squared value of the GDP growth as defined above.

Political rights and civil liberties Source: Freedom House (2013)

A country is scored for each of 10 political rights indicators and 15 civil liberties indicators. The average of the score gives the freedom rating: Free (1.0 to 2.5 ), Partly Free (3.0 to 5.0), or Not Free (5.5 to 7.0)

Dummy freedom (+ve) The dummy takes the value of one if a country is assigned a "Free" status for political rights and civil liberties, and zero otherwise.

Roychoudhury and Lawson $(2010)$

\section{Panel B: Variables for the Cox regression analysis of rating changes ( $D=$ downgrades, $U=$ upgrades)}

National culture variables: As defined above, Power distance index (PDI), Individualism (IDV) vs collectivism, Masculinity (MAS) vs. femininity, Uncertainty avoidance index (UAI), Long-term (LT) vs short-term (ST) orientation

S\&P's rating data. Source: S\&P's Sovereign Ratings History (30 September 2017)

Moody's rating data. Source: Moody's Investors Service (14 June 2013)

Current rating grade (D:-ve; The rating grade of the rating transition being analysed.

Alsakka, ap Gwilym (2009), Hill et al. (2010)

U:-ve)

Dummy lag one downgrade The dummy takes the value of one if the lag one rating ends with a downgrade, and zero

(D:+ve; U:-ve)

Drior fallen angel

Alsakka and ap Gwilym (2009, 2010), Hill et al. (2010), Dang and Partington (2014), Dang (2018)

(D/U:?)

This variable takes the value of one if a country experienced being a fallen angel (a downgrade from an investment-grade rating to a speculative-grade rating)

Age since first rated (D/U:?) This time-varying variable measures the duration since a country was first rated

Lag one duration (D:-ve; The duration (in years) of the rating immediately preceding the rating being analysed

U:-ve)

Dummy prior default

(D:-ve; U:+ve)

This dummy takes the value of one if a country experienced a foreign currency-

denominated debt default prior to the rating under study, and zero otherwise.

Source: S\&P Global Ratings' Credit Research (2013)

Vazza, Aurora and Schneck (2005), Guettler and

Wahrenburg (2007), Dang and Partington (2014), Dang (2018)

Altman (1998), Dang and Partington (2014), Dang (2018)

Alsakka and ap Gwilym (2009), Bannier and Hirsch (2010),

Dang and Partington (2014), Dang (2018)

Cantor and Packard (1996), Hu et al. (2002), Afonso (2003), Mora (2006), Hill et al. (2010), Dang (2018)

\section{S\&P's outlook. Source: S\&P's Sovereign Ratings History (30 September 2017)}

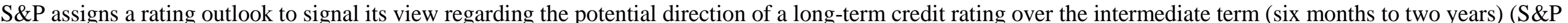

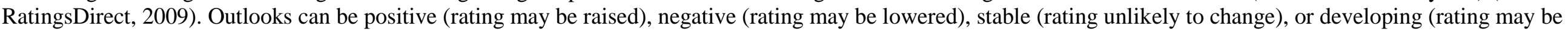
raised or lowered)

Moody's outlook. Source: Moody’s Investors Service (14 June 2013) 
Dummy negative outlook

(D:+ve; U:-ve)

Dummy positive outlook

(D:-ve; U:+ve)
This time-varying variable takes the value of one if a country was assigned a negative outlook by S\&P (Moody's), and zero otherwise.

This time-varying variable takes the value of one if a country was assigned a positive outlook by S\&P (Moody's), and zero otherwise.
Vazza, Leung, Alsati and Katz (2005), Hill et al. (2010), Bannier and Hirsch (2010), Alsakka and ap Gwilym (2012), Dang (2018)

Vazza et al. (2005), Hill et al. (2010), Bannier and Hirsch (2010), Alsakka and ap Gwilym (2012), Dang (2018)

Macroeconomic and financial conditions Source: World Bank databases unless otherwise stated

Dummy debt crisis

(D:+ve; U:-ve)

Dummy OECD member (D/U:?)

Change in GDP per capita (D:-ve; U:+ve)

Change in real GDP growth rate (D/U:?)

Change in inflation (D/U:?) The change in the inflation rate over the year prior to the start of the rating.

Change in current account The change in the current account to GDP ratio over the year prior to the start of the to GDP (D:-ve; U:+ve) otherwise. rating under study, and zero otherwise.

The change in real GDP per capita over the year prior to the start of the rating.

The change in the real GDP growth rate over the year prior to the start of the rating. rating.
This variable takes a value of one if a rating is assigned to a country during a period of sovereign debt and/ or banking crisis as defined in Manasse, Roubini, Schimmelpfennig (2003), Laeven and Valencia (2012), or De Paoli, Hoggarth, Saporta (2009), and zero

This variable takes a value of one if a country is a member of the OECD at the start of the

Please see references for macro-economic variables above.

\section{Political rights and civil liberties Source: Freedom House (2013)}

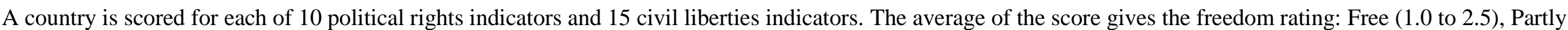
Free (3.0 to 5.0), or Not Free (5.5 to 7.0).

$\begin{aligned} & \text { Dummy freedom (D:-ve; } \\ & \text { U:+ve) }\end{aligned}$
otherwise.

This table lists the variables used in the ordered probit regression and the Cox hazard regression. The table includes the data sources, variable names and definitions, and references to relevant studies that have used these variables. Variable names are followed by the expected coefficient signs (in blue). For ordered probit analysis of rating levels (Panel A), an expected negative sign is denoted as -ve, an expected positive sign is denoted as +ve, no prior expectation is denoted as ?. For rating change Cox's hazard analysis (Panel B), an expected negative (positive) sign on downgrades is denoted as D:-ve (D:+ve), an expected negative (positive) sign on upgrades is denoted as U:-ve (U:+ve), no prior expectation on downgrades and upgrades is denoted as D/U:?. Untabulated pairwise correlations and untabulated variance inflation factors for the ordered probit variables and Cox's hazard model variables do not suggest any multicollinearity problem. 
Table 3 Descriptive statistics for national culture

Panel A: Descriptive statistics for culture variables, S\&P's sample for probit model $(n=1764)$

\begin{tabular}{lccccc}
\hline & Mean & Median & Std Dev & Min & Max \\
\hline Power distance index & 60.69 & 64 & 20.83 & 11 & 104 \\
Individualism & 43.65 & 38 & 22.32 & 12 & 91 \\
Masculinity & 48.21 & 48 & 20.11 & 5 & 110 \\
Uncertainty avoidance index & 67.03 & 68 & 22.58 & 8 & 112 \\
Long-term orientation & 45.24 & 44 & 22.72 & 4 & 100 \\
\hline
\end{tabular}

Panel B: Descriptive statistics for culture variables, Moody's sample for probit model $(n=1606)$

\begin{tabular}{lccccc}
\hline & Mean & Median & Std Dev & Min & Max \\
\hline Power distance index & 59.75 & 63 & 20.94 & 11 & 104 \\
\hline Individualism & 45.30 & 38 & 22.40 & 12 & 90 \\
\hline Masculinity & 48.47 & 50 & 20.37 & 5 & 110 \\
\hline Uncertainty avoidance index & 66.42 & 68 & 22.64 & 8 & 112 \\
\hline Long-term orientation & 45.55 & 44 & 21.70 & 4 & 100 \\
\hline
\end{tabular}

Panel C: Descriptive statistics for culture variables, S\&P's sample for Cox's hazard model $(n=382)$

\begin{tabular}{lccccc}
\hline & Mean & Median & Std Dev & Min & Max \\
\hline Power distance index & 65.54 & 66 & 19.28 & 11 & 104 \\
\hline Individualism & 38.05 & 36 & 19.42 & 12 & 91 \\
\hline Masculinity & 50.29 & 49 & 19.74 & 5 & 110 \\
\hline Uncertainty avoidance index & 71.68 & 76 & 21.77 & 8 & 112 \\
\hline Long-term orientation & 45.85 & 45 & 23.56 & 4 & 100 \\
\hline
\end{tabular}

Panel D: Descriptive statistics for culture variables, Moody's sample for Cox's hazard model $(n=303)$

\begin{tabular}{lccccc}
\hline & Mean & Median & Std Dev & Min & Max \\
\hline Power distance index & 64.97 & 66 & 19.06 & 13 & 104 \\
\hline Individualism & 39.58 & 37 & 20.05 & 12 & 90 \\
\hline Masculinity & 49.75 & 50 & 19.49 & 5 & 110 \\
\hline Uncertainty avoidance index & 70.44 & 75 & 22.55 & 8 & 112 \\
\hline Long-term orientation & 44.91 & 44 & 21.81 & 7 & 100 \\
\hline
\end{tabular}

This table shows the descriptive statistics for scores on the dimensions of culture across the samples used in the study. 
Table 4 Probit model for S\&P's and Moody's ratings

\begin{tabular}{|c|c|c|c|c|c|c|}
\hline \multirow[b]{2}{*}{ Variables } & \multicolumn{3}{|c|}{ S\&P's sample } & \multicolumn{3}{|c|}{ Moody's sample } \\
\hline & $\begin{array}{c}\text { Numeric culture } \\
\text { score }\end{array}$ & $\begin{array}{l}\text { Culture } \\
\text { dummy }\end{array}$ & Probability & $\begin{array}{c}\text { Numeric } \\
\text { culture score }\end{array}$ & $\begin{array}{l}\text { Culture } \\
\text { dummy }\end{array}$ & Probability \\
\hline \multicolumn{7}{|l|}{ Culture } \\
\hline Power distance index (-ve) & $0.0101 *$ & & 0.0894 & 0.0045 & & 0.4467 \\
\hline Individualism (+ve) & $0.0101 *$ & & 0.0699 & $0.0114 * *$ & & 0.0403 \\
\hline Masculinity (?) & $-0.0123 * * *$ & & 0.0089 & $-0.0074 *$ & & 0.098 \\
\hline Uncertainty avoidance index (-ve) & $-0.009 *$ & & 0.0772 & $-0.0088 *$ & & 0.0633 \\
\hline Long-term orientation (?) & $0.0099 * * *$ & & 0.0062 & $0.009 * *$ & & 0.041 \\
\hline Dummy large power distance(-ve) & & $0.4526 * *$ & 0.0353 & & 0.2558 & 0.2647 \\
\hline Dummy individualism (+ve) & & $0.4161 *$ & 0.0652 & & $0.4703 *$ & 0.0619 \\
\hline Dummy masculine (?) & & -0.1604 & 0.4389 & & -0.2016 & 0.3072 \\
\hline Dummy strong UAI (-ve) & & $-0.392 * *$ & 0.0453 & & $-0.599 * * *$ & 0.0043 \\
\hline Dummy long-term orientation (?) & & $0.3903 * *$ & 0.0486 & & 0.2011 & 0.3139 \\
\hline \multicolumn{7}{|l|}{ Controls } \\
\hline Dummy prior default & $-1.365 * * *$ & $-1.292 * * *$ & $0.000 / 0.000$ & $-1.4437 * * *$ & $-1.2656 * * *$ & $0.000 / 0.000$ \\
\hline Dummy OECD member & 0.4104 & 0.3909 & $0.226 / 0.225$ & $0.7098 * *$ & $0.7305^{* *}$ & $0.026 / 0.02$ \\
\hline GDP per capita & $0.0001 * * *$ & $0.0001 * * *$ & $0.000 / 0.000$ & $0.0001 * * *$ & $0.0001 * * *$ & $0.000 / 0.000$ \\
\hline GDP growth & $0.1929 * * *$ & $0.1881 * * *$ & $0.000 / 0.000$ & $0.1807 * * *$ & $0.1866 * * *$ & $0.000 / 0.000$ \\
\hline Square of GDP growth & $-0.0093^{* *}$ & $-0.0078^{*}$ & $0.047 / 0.078$ & $-0.011 * *$ & $-0.0123 * *$ & $0.015 / 0.012$ \\
\hline Inflation & $-0.0018 * * *$ & $-0.0015^{* *}$ & $0.003 / 0.015$ & $-0.0011 * * *$ & $-0.0009 * * *$ & $0.000 / 0.000$ \\
\hline Current account surplus/GDP & 0.0202 & 0.0209 & $0.17 / 0.123$ & 0.0079 & 0.0096 & $0.526 / 0.429$ \\
\hline Dummy freedom & 0.2429 & 0.1802 & $0.226 / 0.357$ & 0.1662 & 0.0476 & $0.422 / 0.802$ \\
\hline Std dev of world stock market index & $-0.1281 * * *$ & $-0.1315^{* * *}$ & $0.000 / 0.000$ & -0.0235 & -0.0157 & $0.56 / 0.68$ \\
\hline QIC statistic & 7348.4 & 7417.4 & & 6674.4 & 6700.8 & \\
\hline $\begin{array}{l}\text { QIC Statistic for a model only } \\
\text { containing control variables }\end{array}$ & 7517.9 & 7517.9 & & 6801.1 & 6801.1 & \\
\hline
\end{tabular}

This table presents the results from estimating an ordered probit model for rating levels. The S\&P's (Moody's) sample includes 1764 (1606) ratings. For brevity reason, intercept estimates are not presented. For both samples, the probabilities of rating levels having higher ordered values in Table 1 (column 2) are modelled. Descriptions of the independent variables are given in Table 2 Panel A. The independent variables for culture are coded as numeric variables and dummy variables. Dummy variables take a value of one if the culture score is greater than or equal to the mean and zero otherwise. Significant coefficients based on robust standard errors (clustered at country) are shown in bold, with ***, ** and * representing significance at the $0.01,0.05$ and 0.10 levels respectively. For the control variables the probabilities are given in the form 0.001/0.002, representing the significance of the coefficients for models with numeric culture scores and dummy variables for culture respectively. 
Table 5 Cox model for S\&P's rating changes

\begin{tabular}{|c|c|c|c|c|c|c|c|c|c|c|c|c|}
\hline \multirow[b]{3}{*}{ Variables } & \multicolumn{6}{|c|}{ S\&P's sample: Numeric Culture Score } & \multicolumn{6}{|c|}{ S\&P's sample: Culture Dummy } \\
\hline & \multicolumn{3}{|c|}{ Downgrade } & \multicolumn{3}{|c|}{ Upgrade } & \multicolumn{3}{|c|}{ Downgrade } & \multicolumn{3}{|c|}{ Upgrade } \\
\hline & Coefficient & $\begin{array}{l}\text { Hazard } \\
\text { ratio }\end{array}$ & Prob & Coefficient & $\begin{array}{l}\text { Hazard } \\
\text { ratio }\end{array}$ & Prob & Coefficient & $\begin{array}{l}\text { Hazard } \\
\text { ratio }\end{array}$ & Prob & Coefficient & $\begin{array}{l}\text { Hazard } \\
\text { ratio }\end{array}$ & Prob \\
\hline \multicolumn{13}{|l|}{ National culture dimensions } \\
\hline Power distance index & -0.0119 & 0.988 & 0.202 & 0.00864 & 1.009 & 0.224 & & & & & & \\
\hline Individualism & -0.0141 & 0.986 & 0.123 & $0.0118 * *$ & 1.012 & 0.028 & & & & & & \\
\hline Masculinity & -0.0055 & 0.995 & 0.289 & -0.0066 & 0.993 & 0.159 & & & & & & \\
\hline Uncertainty avoidance index (UAI) & 0.0047 & 1.005 & 0.457 & 0.00447 & 1.004 & 0.278 & & & & & & \\
\hline Long-term orientation & 0.00586 & 1.006 & 0.380 & $0.2236 * * *$ & 1.015 & 0.001 & & & & & & \\
\hline Dummy large power distance index & & & & & & & $-0.7726 * * *$ & 0.462 & 0.003 & 0.29305 & 1.341 & 0.1968 \\
\hline Dummy individualism & & & & & & & $-0.8035 *$ & 0.448 & 0.058 & $0.52238 * *$ & 1.686 & 0.0232 \\
\hline Dummy masculine & & & & & & & -0.0349 & 0.966 & 0.889 & -0.1626 & 0.85 & 0.3767 \\
\hline Dummy strong UAI & & & & & & & -0.1611 & 0.851 & 0.646 & 0.18845 & 1.207 & 0.2263 \\
\hline Dummy long-term orientation & & & & & & & 0.64295 & 1.902 & 0.117 & 0.2110 & 1.235 & 0.2026 \\
\hline \multicolumn{13}{|l|}{ S\&P's rating } \\
\hline Current rating grade & -0.0564 & 0.945 & 0.102 & $-0.1699 * * *$ & 0.844 & 0.000 & $-0.0671 * *$ & 0.935 & 0.041 & $-0.1205 * * *$ & 0.886 & 0.000 \\
\hline Dummy lag one downgrade & $0.5528 * *$ & 1.738 & 0.029 & $-0.8056 * * *$ & 0.447 & 0.003 & $0.5177 * 3$ & 1.678 & 0.036 & $-0.7025 * * *$ & 0.495 & 0.005 \\
\hline Lag one rating duration & -0.0138 & 0.986 & 0.569 & -0.0356 & 0.965 & 0.459 & -0.0187 & 0.981 & 0.416 & -0.0459 & 0.955 & 0.417 \\
\hline Age since first rated (time-varying) & -0.0042 & 0.996 & 0.810 & 0.0392 & 1.04 & 0.021 & 0.0001 & 1.000 & 0.996 & $0.0348 * *$ & 1.035 & 0.035 \\
\hline Dummy prior fallen angel & -0.1564 & 0.855 & 0.588 & 0.1096 & 1.116 & 0.627 & -0.2358 & 0.79 & 0.379 & -0.0250 & 0.975 & 0.926 \\
\hline Dummy negative outlook (time-varying) & $1.6401 * * *$ & 5.156 & 0.000 & $-15.3260 * * *$ & 0.000 & 0.000 & $1.6013 * * *$ & 4.959 & 0.000 & $-15.264 * * *$ & 0.000 & 0.000 \\
\hline Dummy positive outlook (time-varying) & $-2.4201 * *$ & 0.089 & 0.011 & $1.9529 * * *$ & 7.049 & 0.001 & $-2.4222 * *$ & 0.089 & 0.014 & $2.0098 * * *$ & 7.462 & 0.000 \\
\hline
\end{tabular}




\begin{tabular}{|c|c|c|c|c|c|c|c|c|c|c|c|c|}
\hline \multirow[b]{3}{*}{ Variables } & \multicolumn{6}{|c|}{ S\&P's sample: Numeric Culture Score } & \multicolumn{6}{|c|}{ S\&P's sample: Culture dummy } \\
\hline & \multicolumn{3}{|c|}{ Downgrade } & \multicolumn{3}{|c|}{ Upgrade } & \multicolumn{3}{|c|}{ Downgrade } & \multicolumn{3}{|c|}{ Upgrade } \\
\hline & Coefficient & $\begin{array}{l}\text { Hazard } \\
\text { ratio }\end{array}$ & Prob & Coefficient & $\begin{array}{l}\text { Hazard } \\
\text { ratio }\end{array}$ & Prob & Coefficient & $\begin{array}{l}\text { Hazard } \\
\text { ratio }\end{array}$ & Prob & Coefficient & $\begin{array}{l}\text { Hazard } \\
\text { ratio }\end{array}$ & Prob \\
\hline \multicolumn{13}{|l|}{$\begin{array}{l}\text { Macro-economic and financial } \\
\text { conditions }\end{array}$} \\
\hline Dummy prior default & -0.5951 & 0.551 & 0.376 & 0.4345 & 1.544 & 0.260 & -1.1453 & 0.318 & 0.201 & 0.6669 & 1.948 & 0.139 \\
\hline Dummy debt crisis & $0.9818 * * *$ & 2.669 & 0.000 & -0.0896 & 0.914 & 0.761 & $1.0781 * * *$ & 2.939 & 0.000 & 0.0506 & 1.052 & 0.845 \\
\hline Dummy OECD member & -0.0918 & 0.912 & 0.746 & -0.2627 & 0.769 & 0.317 & -0.3038 & 0.738 & 0.353 & -0.2271 & 0.797 & 0.343 \\
\hline Change in GDP per capita & -4.7255 & 0.009 & 0.194 & 2.1114 & 8.259 & 0.574 & -5.9056 & 0.003 & 0.088 & 2.8015 & 16.469 & 0.419 \\
\hline Change in real GDP growth rate & -0.0351 & 0.966 & 0.451 & $-0.0556 * *$ & 0.946 & 0.017 & -0.0239 & 0.976 & 0.594 & $-0.0544 * *$ & 0.947 & 0.022 \\
\hline Change in inflation & 0.0031 & 1.003 & 0.482 & 0.0002 & 1 & 0.391 & 0.0064 & 1.006 & 0.206 & 0.0003 & 1.000 & 0.376 \\
\hline Change in current account to GDP & $-0.0865 * * *$ & 0.917 & 0.001 & 0.0332 & 1.034 & 0.239 & $-0.0981 * * *$ & 0.907 & 0.000 & 0.0339 & 1.035 & 0.163 \\
\hline \multicolumn{13}{|l|}{ Political rights and civil liberties } \\
\hline Dummy freedom & 0.0784 & 1.082 & 0.788 & -0.1476 & 0.863 & 0.518 & 0.05109 & 1.052 & 0.854 & -0.0141 & 0.986 & 0.948 \\
\hline Likelihood ratio $\chi^{2}$ adding culture & $18.92 * * *$ & & 0.002 & $33.89 * * *$ & & 0.000 & $27.72 * * *$ & & 0.000 & $17.286 * * *$ & & 0.004 \\
\hline
\end{tabular}

This table presents the results from estimating a stratified Cox model for rating changes by S\&P, with separate models for upgrades and downgrades. The S\&P's sample used to estimate the stratified Cox hazard model includes 382 ratings of which 149 are downgrades and 165 are upgrades. Descriptions of the independent variables are given in Table 2 Panel B. The independent variables for culture are coded as numeric scores and dummy variables. Dummy variables take a value of one if the culture score is greater than or equal to the mean and zero otherwise. Significant coefficients are shown in bold, with $* * *, * *$ and $*$ representing significance at the $0.01,0.05$ and 0.10 levels respectively using the Wald test. The percentage change in the hazard for a one-unit change in an independent variable can be obtained by subtracting one from the hazard ratio. The likelihood ratio chi square is based on a comparison of models with culture variables added versus a model containing all the variables except the culture variables. 
Table 6 Cox model for Moody's rating changes

\begin{tabular}{|c|c|c|c|c|c|c|c|c|c|c|c|c|}
\hline \multirow[b]{3}{*}{ Variables } & \multicolumn{6}{|c|}{ Moody's sample: Numeric Culture Score } & \multicolumn{6}{|c|}{ Moody's sample: Culture Dummy } \\
\hline & \multicolumn{3}{|c|}{ Downgrade } & \multicolumn{3}{|c|}{ Upgrade } & \multicolumn{3}{|c|}{ Downgrade } & \multicolumn{3}{|c|}{ Upgrade } \\
\hline & Coefficient & $\begin{array}{l}\text { Hazard } \\
\text { ratio }\end{array}$ & Prob. & Coefficient & $\begin{array}{l}\text { Hazard } \\
\text { ratio }\end{array}$ & Prob. & Coefficient & $\begin{array}{l}\text { Hazard } \\
\text { ratio }\end{array}$ & Prob. & Coefficient & $\begin{array}{l}\text { Hazard } \\
\text { ratio }\end{array}$ & Prob. \\
\hline \multicolumn{13}{|l|}{ National culture dimensions } \\
\hline Power distance index & -0.0007 & 0.999 & 0.906 & $0.01939 * * *$ & 1.02 & 0.005 & & & & & & \\
\hline Individualism & -0.0122 & 0.988 & 0.106 & -0.0013 & 0.999 & 0.843 & & & & & & \\
\hline Masculinity & -0.003 & 0.997 & 0.561 & -0.0049 & 0.995 & 0.457 & & & & & & \\
\hline Uncertainty avoidance index (UAI) & 0.00671 & 1.007 & 0.168 & 0.00834 & 1.008 & 0.183 & & & & & & \\
\hline Long-term orientation & $-0.0201 * * *$ & 0.98 & 0.000 & 0.00263 & 1.003 & 0.582 & & & & & & \\
\hline Dummy large power distance index & & & & & & & $-0.5355 * *$ & 0.585 & 0.016 & 0.30334 & 1.354 & 0.187 \\
\hline Dummy individualism & & & & & & & $-1.1824 * * *$ & 0.307 & 0.000 & -0.4298 & 0.651 & 0.116 \\
\hline Dummy masculine & & & & & & & 0.2083 & 1.232 & 0.339 & -0.1456 & 0.865 & 0.517 \\
\hline Dummy strong UAI & & & & & & & 0.27344 & 1.314 & 0.228 & 0.19773 & 1.219 & 0.367 \\
\hline Dummy long-term orientation & & & & & & & $-0.4407 *$ & 0.644 & 0.059 & -0.1564 & 0.855 & 0.399 \\
\hline \multicolumn{13}{|l|}{ S\&P's rating } \\
\hline Current rating grade & -0.0082 & 0.992 & 0.858 & $-0.1249 * * *$ & 0.883 & 0.000 & 0.0024 & 1.002 & 0.959 & $-0.1050 * * *$ & 0.900 & 0.000 \\
\hline Dummy lag one downgrade & $1.2576 * *$ & 3.517 & 0.002 & -0.3458 & 0.708 & 0.301 & $1.39643 * * *$ & 4.041 & 0.001 & -0.3096 & 0.734 & 0.340 \\
\hline Lag one rating duration & -0.0205 & 0.98 & 0.609 & -0.0275 & 0.973 & 0.575 & -0.0415 & 0.959 & 0.295 & -0.0263 & 0.974 & 0.609 \\
\hline Age since first rated (time-varying) & -0.0078 & 0.992 & 0.733 & 0.0508 & 1.052 & 0.116 & 0.00753 & 1.008 & 0.745 & 0.02114 & 1.021 & 0.524 \\
\hline Dummy prior fallen angel & $-1.061 * * *$ & 0.346 & 0.0049 & -0.2312 & 0.794 & 0.475 & $-0.9733 * *$ & 0.378 & 0.024 & -0.3553 & 0.701 & 0.236 \\
\hline Dummy negative outlook (time-varying) & $1.5515 * * *$ & 4.718 & 0.000 & $-15.067 * * *$ & 0.000 & 0.000 & $1.62816 * * *$ & 5.095 & 0.000 & $-15.043 * * *$ & 0.000 & 0.000 \\
\hline Dummy positive outlook (time-varying) & $-15.901 * * *$ & 0.000 & 0.000 & $1.7028 * * *$ & 5.489 & 0.000 & $-15.927 * * *$ & 0.000 & 0.000 & $1.70981 * * *$ & 5.528 & 0.000 \\
\hline
\end{tabular}




\begin{tabular}{|c|c|c|c|c|c|c|c|c|c|c|c|c|}
\hline \multirow[b]{3}{*}{ Variables } & \multicolumn{6}{|c|}{ Moody's sample: Numeric Culture Score } & \multicolumn{6}{|c|}{ Moody's sample: Culture dummy } \\
\hline & \multicolumn{3}{|c|}{ Downgrade } & \multicolumn{3}{|c|}{ Upgrade } & \multicolumn{3}{|c|}{ Downgrade } & \multicolumn{3}{|c|}{ Upgrade } \\
\hline & Coefficient & $\begin{array}{l}\text { Hazard } \\
\text { ratio }\end{array}$ & Prob. & Coefficient & $\begin{array}{l}\text { Hazard } \\
\text { ratio }\end{array}$ & Prob. & Coefficient & $\begin{array}{l}\text { Hazard } \\
\text { ratio }\end{array}$ & Prob. & Coefficient & $\begin{array}{l}\text { Hazard } \\
\text { ratio }\end{array}$ & Prob. \\
\hline \multicolumn{13}{|l|}{$\begin{array}{l}\text { Macro-economic and financial } \\
\text { conditions }\end{array}$} \\
\hline Dummy prior default & -0.8254 & 0.438 & 0.207 & 0.46537 & 1.593 & 0.410 & -0.9561 & 0.384 & 0.157 & 0.56306 & 1.756 & 0.2795 \\
\hline Dummy debt crisis & 0.2998 & 1.35 & 0.397 & -0.2899 & 0.748 & 0.336 & 0.22457 & 1.252 & 0.478 & -0.095 & 0.909 & 0.7755 \\
\hline Dummy OECD member & $0.78377 * * *$ & 2.19 & 0.001 & -0.0326 & 0.968 & 0.912 & $0.5517 * *$ & 1.736 & 0.025 & 0.05959 & 1.061 & 0.8161 \\
\hline Change in GDP per capita & -4.3332 & 0.013 & 0.445 & -0.3656 & 0.694 & 0.893 & -5.0758 & 0.006 & 0.294 & 0.01124 & 1.011 & 0.9966 \\
\hline Change in real GDP growth rate & -0.0677 & 0.935 & 0.119 & -0.0021 & 0.998 & 0.924 & -0.0688 & 0.934 & 0.100 & -0.0061 & 0.994 & 0.7638 \\
\hline Change in inflation & $-0.0017 * * *$ & 0.998 & 0.000 & -0.0004 & 1.000 & 0.628 & $-0.0019 * * *$ & 0.998 & 0.000 & -0.0006 & 0.999 & 0.5668 \\
\hline Change in current account to GDP & -0.0591 & 0.943 & 0.103 & $0.0342 *$ & 1.035 & 0.099 & -0.0694 & 0.933 & 0.055 & 0.02708 & 1.027 & 0.1705 \\
\hline \multicolumn{13}{|l|}{ Political rights and civil liberties } \\
\hline Dummy freedom & 0.1273 & 1.136 & 0.6417 & -0.2103 & 0.810 & 0.399 & 0.2327 & 1.262 & 0.396 & -0.1472 & 0.863 & 0.6007 \\
\hline Likelihood ratio $\chi^{2}$ adding culture & 30.33*** & & 0.000 & $17.768 * * *$ & & 0.003 & $30.742 * * *$ & & 0.000 & $14.78 * *$ & & 0.0113 \\
\hline
\end{tabular}

This table presents the results from estimating a stratified Cox model for rating changes by Moody's, with separate models for upgrades and downgrades. The Moody's sample used to estimate the stratified Cox hazard model includes 303 ratings of which 106 are downgrades and 135 are upgrades. Descriptions of the independent variables are given in Table 2 Panel B. The independent variables for culture are coded as numeric scores and dummy variables. Dummy variables take a value of one if the culture score is greater than or equal to the mean and zero otherwise. Significant coefficients are shown in bold, with $* * *, * *$ and $*$ representing significance at the $0.01,0.05$ and 0.10 levels respectively using the Wald test. The percentage change in the hazard for a one-unit change in an independent variable can be obtained by subtracting one from the hazard ratio. The likelihood ratio chi-square is based on a comparison of models with culture variables added versus a model containing all the variables except the culture variables. 
Table 7 Two-stage residual inclusion analysis

Two-stage residual inclusion (2SRI)

\begin{tabular}{|c|c|c|c|c|c|c|c|}
\hline & & & & & & & \multirow{4}{*}{$\begin{array}{c}\text { ordered probit } \\
\text { Robust SEs clustered at country } \\
\text { (8) Ratings (Coefficient, SE) }\end{array}$} \\
\hline & & First- & tage regres & ions & & Second-stage ordered probit & \\
\hline \multirow[t]{2}{*}{ Dependent variable } & \multicolumn{5}{|c|}{ Robust standard errors (SEs) clustered at country } & Bootstrap SEs, 929 iterations & \\
\hline & (2) PDI & (3) IDV & (4) MAS & (5) UAI & (6) LTO & (7) Ratings (Coefficient, SE) & \\
\hline \multirow{6}{*}{$\begin{array}{l}\text { Instrumental variables (IVs) } \\
\text { Tu-vos differentiation ( } t \text { __diff) } \\
\text { Historical diseases } \\
\text { Gender inequality } \\
\text { Catholic minus Protestant (religion) } \\
\text { Logarithm of pre-1500 max calories } \\
\text { (historical crop yield) }\end{array}$} & & & & & & & \\
\hline & $9.5465^{* *}$ & $-14.7516^{* * *}$ & $-11.1777 * * *$ & 5.4095 & $14.6752 * * *$ & NA & NA \\
\hline & 2.9975 & $-12.3017 * * *$ & 0.4557 & -2.3739 & -3.3019 & NA & NA \\
\hline & 1.6414 & -8.8593 & 26.6359 & 20.4716 & $-62.1569 * * *$ & NA & NA \\
\hline & $0.0936 * * *$ & -0.0358 & $0.1485^{* * *}$ & $0.1755^{* * *}$ & -0.045 & NA & NA \\
\hline & $-0.1439 * * *$ & 0.0368 & -0.0197 & $-0.1778 * * *$ & $0.0823 * *$ & NA & NA \\
\hline Power distance index (PDI) & NA & NA & NA & NA & NA & $.1137 * * *(.0284)$ & $0.0101 *(.00597)$ \\
\hline Individualism (IDV) & NA & NA & NA & NA & NA & $.0462 * * *(.0085)$ & $0.0101 *(.0056)$ \\
\hline Masculinity (MAS) & NA & NA & NA & NA & NA & $.0578 * * *(.0107)$ & $-0.0123 * * *(.0047)$ \\
\hline Uncertainty avoidance (UAI) & NA & NA & NA & NA & NA & $-.0924 * * *(.0208)$ & $-0.009 *(.00485)$ \\
\hline Long-term orientation (LTO) & NA & NA & NA & NA & NA & $.04476 * * *(.004)$ & $0.0099 * * *(.0035)$ \\
\hline Fitted residual_PDI & NA & NA & NA & NA & NA & $-0.1506 * * *(.0285)$ & $\mathrm{NA}$ \\
\hline Fitted residual_IDV & NA & NA & NA & NA & NA & $-0.0509 * * *(.0084)$ & NA \\
\hline Fitted residual_MAS & NA & NA & NA & NA & NA & $-0.0738 * * * \quad(.0110)$ & NA \\
\hline Fitted residual_UAI & NA & NA & NA & NA & NA & $0.108 * * * \quad(.0208)$ & NA \\
\hline Fitted residual_LTO & NA & NA & NA & NA & NA & $-0.0375 * * *(.0041)$ & NA \\
\hline Control variables & Yes & Yes & Yes & Yes & Yes & Yes & Yes \\
\hline Number of observations & 1764 & 1764 & 1764 & 1764 & 1764 & 1764 & 1764 \\
\hline $\mathrm{R}^{2}$ models with IVs & $58.6 \%$ & $67.8 \%$ & $29.2 \%$ & $40.8 \%$ & $37.9 \%$ & Pseudo $\mathrm{R}^{2}: 29.15 \%$ & Pseudo $\mathrm{R}^{2}: 28.02 \%$ \\
\hline $\mathrm{R}^{2}$ models without IVs & $48.7 \%$ & $53 \%$ & $7.3 \%$ & $23 \%$ & $12.7 \%$ & Wald $\chi 2: 1312.67 * * *$ & Wald $\chi 2: 246.13^{* * *}$ \\
\hline $\mathrm{F}(5,76)$ statistics & $10.46 * * *$ & $6.85^{* * *}$ & $7.11 * * *$ & $8.14 * * *$ & $10.92 * * *$ & Log-likelihood: -3411.55 & Log-likelihood: -3466.14 \\
\hline
\end{tabular}

This table reports the results of the 2SRI procedure for S\&P rating levels of 77 countries in the sample. Columns (2)-(6) include the results of the first-stage regressions. The probabilities of higher rating levels according to culture are modelled in columns (7) and (8). These ordered probit models were estimated using maximum likelihood. Column (7) includes the result (coefficient, standard error) of the second stage ordered probit. Fitted residual_PDI is the residual generated from the firststage OLS regression where PDI is the dependent variable, and so on. Column (8) includes the results (coefficient, standard error) of the endogeneity-uncorrected ordered probit, and the coefficients exactly match those as taken from Table 4 (column 2). Coefficient estimates are given first followed by the corresponding p-values (*** p-value $\leq 1 \%, * * 1 \%<$ p-value $\leq 5 \%, * 5 \%<$ p-value $\leq 10 \%)$. 
Figure 1 Distribution of ratings for downgrades and upgrades

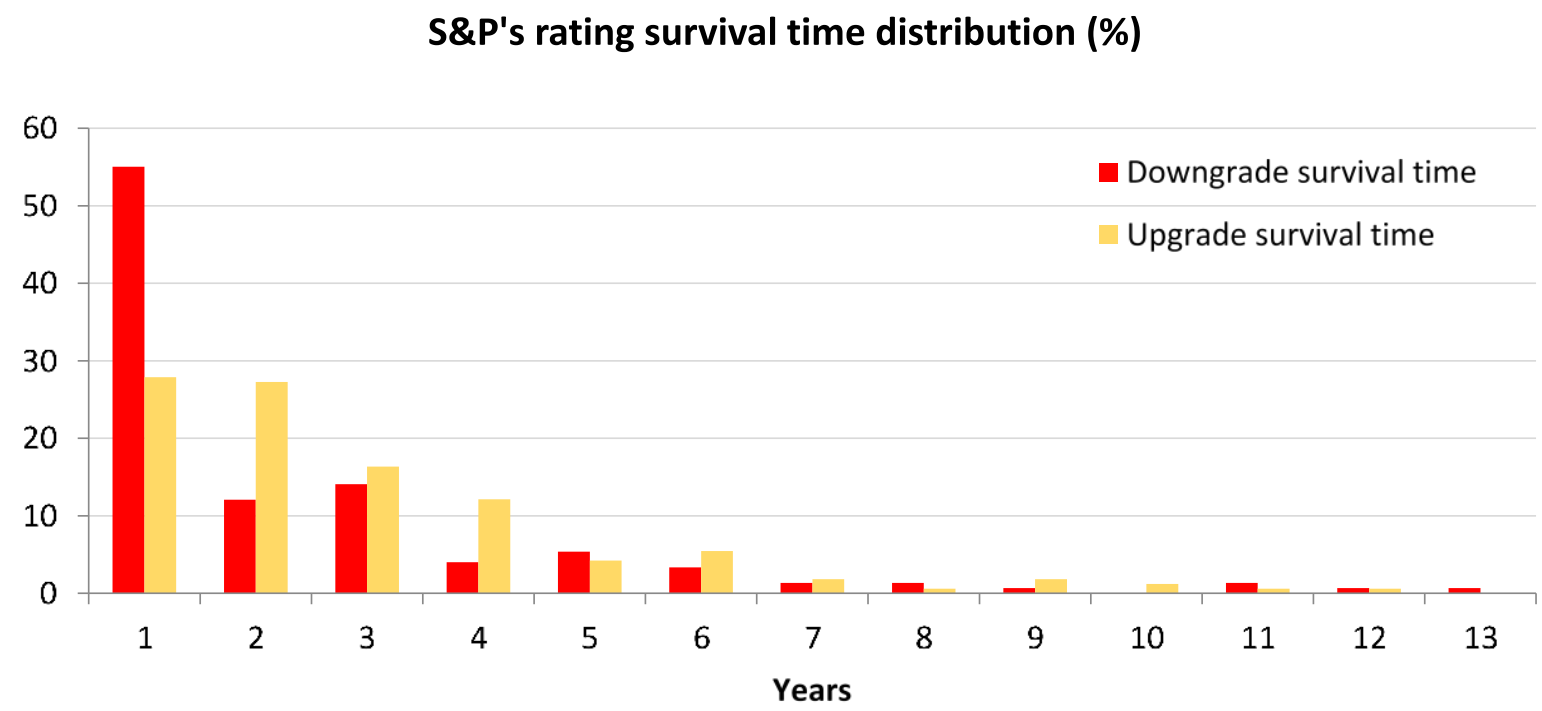

Moody's rating survival time distribution (\%)

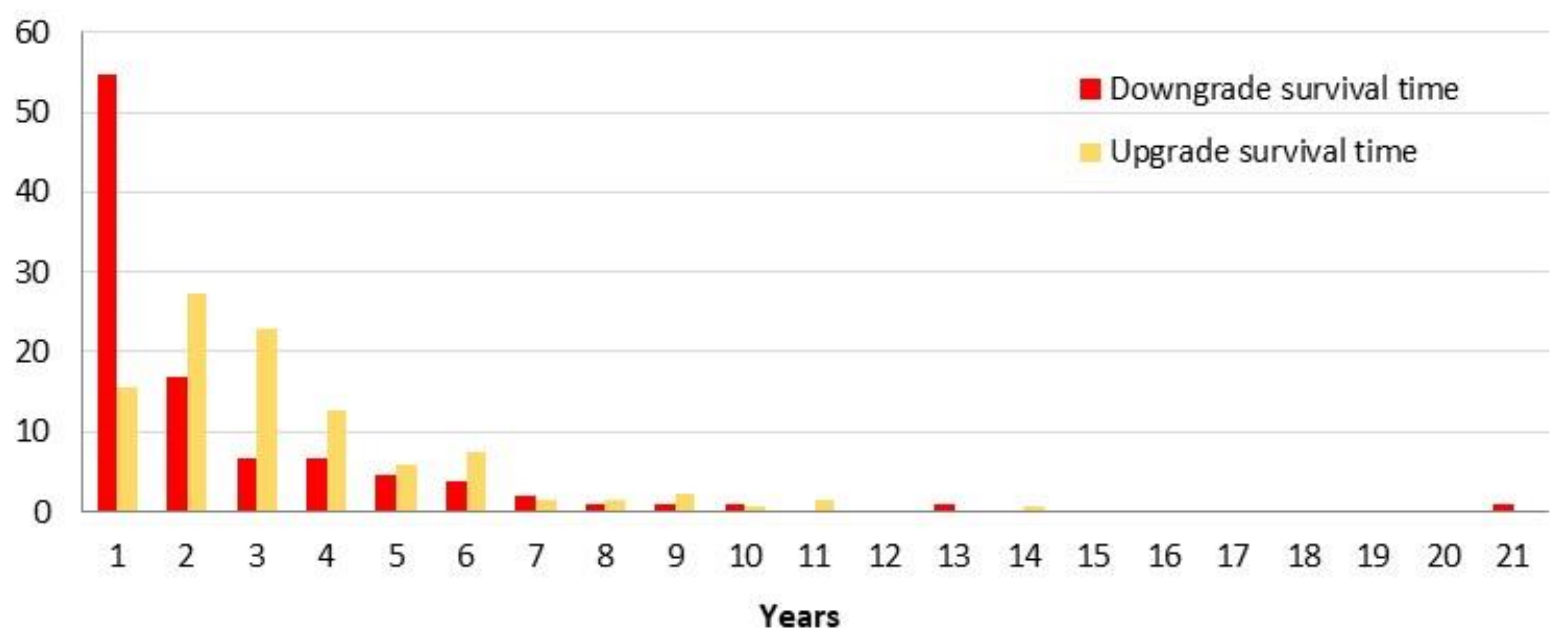

This figure shows the distribution of S\&P's and Moody's ratings for upgrades and downgrades by the duration (survival time) of the ratings. The histogram bars represent the percentage of total observations contained within each class of rating duration. Duration is the spell of time a country stays in a rating grade measured from the time a rating is assigned to a country until the time the rating is changed by one notch or is censored. A country often contribute multiple rating changes to the study. The S\&P's (Moody's) sample model includes 382 (303) ratings of which 149 (106) are downgrades and 165 (135) are upgrades. 